\title{
Experimental Investigation of Dimensional Variation in Laser- machined Micro-channels produced in Titanium Alloy
}

\author{
Naveed Ahmed ${ }^{1,2,3,4}$, Saied Darwish ${ }^{1,2,3}$, Abdulrahman M. Alahmari ${ }^{1,2,3}$ \\ anaveed@ksu.edu.sa; darwish@ksu.edu.sa; alahmari@ksu.edu.sa \\ 1. Princess Fatima Alnijiris's Research Chair for Advanced Manufacturing Technology (FARCAMT Chair), King Saud \\ University, Riyadh - Saudi Arabia. \\ 2. Industrial Engineering Department, King Saud University, Riyadh - Saudi Arabia. \\ 3. Advanced Manufacturing Institute, King Saud University, Riyadh - Saudi Arabia. \\ 4. Department of Industrial and Manufacturing Engineering, University of Engineering and Technology, Lahore-
} Pakistan.

\begin{abstract}
Micro-channels are extensively used in various engineering applications including micro-channel heat exchangers, micro-channel coolers, micro-channel heat pipes and micro-channel pulsating heat devices widely used in several important and diverse fields such as aerospace, automotive, cooling of gas turbine blades, cryogenic systems, bioengineering and many more. All such fields required different sized micro-channels according to the cooling requirements and installation space constraints. Variation or oversizing/undersizing to the designed channel geometries imparts significant disturbance to fluid flow. In this study, different sized micro-channels of rectangular cross section are fabricated in titanium alloy (Ti-6Al-4V) through Nd:YAG pulsed laser beam micro-milling (LBMM). The variations (in \%) in actual geometrical characteristics from the designed geometries are calculated and observed for various sizes of micro-channels. Laser parametric influences on geometrical characteristics such as channel's top width, bottom width, depth and degree of taperness are categorically evaluated for each size of micro-channel. Finally, the effect of microchannel size on each geometrical variation is evaluated by making a comparison plots of each geometry, each size and each employed laser parameter. The results reveal that the effects of individual laser parameter on each micro-channel size and each geometrical characteristic are different for different sizes and response predictors (geometrical characteristics). It is prominently found that as the micro-channel size increases the variation in channel geometry (oversizing and/or undersizing) decreases.
\end{abstract}

DOI: $10.2961 /$ jlmn.2016.02.0012

Keywords: micro-channels; oversizing, undersizing; variation, Nd:YAG laser; laser beam micro-milling (LBMM), Ti$6 \mathrm{Al}-4 \mathrm{~V}$, geometrical characteristics

\section{Introduction}

In the present era the importance of micro-channels is growingly increased due to their numerous advantages especially in terms of high volume heat flux, miniature sizing, compactness for space-constraint requirements, effectiveness in flow distribution and controlled pressure drop. Thermal duty and energy efficiency requirements have also increased during this period, while the space constraints have become more restrictive. The trend has been drifted towards greater heat transfer rates per unit volume.The wide use of microchannels is in micro heat exchangers, micro-coolers, microheat pipes and micro-pulsating pipes extensively used in the field of aerospace, automotive, refrigeration and air conditioning, solar systems [1], chemical reactors [2], flow boiling heat transfers [3] and [4], liquid dose applications in biomedical sector [5], cryogenic systems used for cancer treatment etc. Thus, the micro-channels are considered as an integral part of such a sophisticated systems [6].

Several materials on which the micro-channel fabrication is required are used in different kinds of applications. The choice of material depends on the requirements and systems where the micro-channels have to serve for cooling applications. For example, copper micro-channels are used for heat sinks cooling [3] and silicon micro-channels for particle physics detectors [7]. Micro-channels in aluminum alloy can be found in [8]. The fabrication of micro-channels in nonmetallic can be found in various studies showing microchannels produced in Polycarbonate (PC) [9], polymethylmethacrylate (PMMA) [10], and glass [11]. Very less study is done on fabrication of micro-channels in hard-tomachine materials like titanium and nickel alloys. Titanium alloy Ti-6Al-4V has been distinguished as one of the most widely used materials in biomedicine for prosthetics and surgical instruments, as well as in other industries as diverse as aerospace and the automotive industry [12].

In terms of micro-channel's cross-sectional shapes, different shapes are reported in literature including rectangular [13], triangular [14], trapezoidal [15] and circular crosssection micro-channels [16]. The most common type of micro-channel cross section found in literature is the open ended v-shaped or u-shaped square/rectangular cross section. The shape and size of micro-channel directly influence the 
fluid flow characteristics, heat transfer process, pressure drop characteristics and two-phase flow instabilities. For example, 100 parallel micro-channels having equal sizes of 100x680 $\mu \mathrm{m}$ have been fabricated in multichannel heat sink used for cooling of micro-electronic central processing unit to study the two-phase flow boiling of R134a refrigerant [17]. In another similar study, the air and water (two-phase) flow performance is studied in hybrid micro-channel solar cell by fabricating an array of rectangular micro-channels with a hydraulic diameter of $667 \mu \mathrm{m}$.

There are many techniques to produce above said sizes and shapes of micro-channels including both the conventional as well as non-conventional techniques. But every manufacturing process has its own limitations. For example, the conventional micro-milling process using micro-tools are commonly used but the high tooling cost, burr formation, material constraints offered by difficult-to-machine materials, chip adhesion, high thrust forces, heat affected zone and striation marks are the obvious drawbacks of conventional micro-milling and consequently restrict the process for precise micro-featuring especially in hard-to-machine materials such as titanium and nickel alloys [18]-[19]. Fabrication of microchannels in Ti-6Al-4V has been realized by E. Vazquez et al. [20] with the help of tungsten carbide micro-tools using CNC machining center. Micro-hot embossing is another potential candidate among the available technique of micro-channel production. The process of micro-hot embossing was utilized by the researchers of [8] while manufacturing an array of micro-channels of size 5-100 $\mu \mathrm{m}$ in aluminum target material. Among non-traditional machining process electric discharge machining $(\mathrm{EDM})$ is considered as relatively good alternative having no material hardness and channel shape restrictions [3] and [21]. But there are also number of problems linked with EDM and wire-EDM such as low productivity, high tool wear rate, lack of precision due to tool wear, unsuitable for batch production or multi-channels [22], thick recast layer (from $2.5 \mu \mathrm{m}$ to $30 \mu \mathrm{m}$ ) [23], and heat affected layer of 40-100 um [23]. Chemical etching is another alternative for the fabrication of micro-channels but it offers troubles of having high aspect-ratio micro-channels [24].

Laser beam micro-milling (LBMM) is considered as among the competent techniques used for micro-fabrications. It is well suited for machining of a wide range of materials; from ductile to hard-to-machine materials. LBMM using $\mathrm{Nd}: \mathrm{YVO}_{4}$ nano-second laser can be found to produce circular cross-sectional micro-channels on soda lime glass [25]. Similarly, femtosecond laser has been utilized by a research team of [26] where they generated micro-features on different polymeric samples. Selection of channel size is also important and should be considered alongside the laser parameters. Wider sized channels with relatively good dimensional accuracy can be more flexibly produced in titanium alloy by $\mathrm{Nd}$ :YAG pulsed laser compared to the accuracy in narrow sized [27]. Likewise, the processing of metals (aluminum and titanium) by laser milling has been documented in [28] where width and depth of micro-features were studied. Aluminum and steel based alloys dealt under nano-second pulsed fiber laser are presented in [29] where the authors examined the effect of laser based parameters on the formation of micronotches. As per their conclusions the micro-notches vary in sizes and the machined width and depth mainly depend on laser power and pulse repetition rate. Another study stated that laser milling is a complex process due to which a variation in depth and width of micro-channel can be soundly observed [30]. They applied Nd:YAG laser to machine micro-channels of size $200 \times 50 \mu \mathrm{m}$. In general, for polymeric materials, the micro-channel's geometry (width and depth) primarily relies on laser power and scanning speed under linear relationship. However, the frequency of laser pulses does not severely affects the channel's depth and width [31].

As the most commonly used shape of micro-channels is square or rectangular cross sectional shape, therefore, in our present study rectangular cross sectional micro-channels were fabricated in titanium alloy (Ti-6Al-4V) through Nd:YAG pulsed laser beam micro-milling (LBMM). As per literature findings different sizes in micro-channels are required depending on the application requirements and the variation in channel size plays important role in fluid flow characteristics. So, we selected five different micro-channel sizes including 100x50 $\mu \mathrm{m}, 200 \times 100 \mu \mathrm{m}, 400 \times 200 \mu \mathrm{m}, 800 \times 400 \mu \mathrm{m}$ and $1000 \times 500 \mu \mathrm{m}$. The objective was to study the geometrical variation of each channel size over the most significant laser parameters. The geometrical configurations under consideration include the micro-channel's top width, bottom width, depth and taperness of sidewalls. The oversizing and/or undersizing in actual machined micro-channels were studied for each of the four geometrical characteristics associated with each of the five micro-channel sizes. Finally, different trends of oversizing/undersizing of geometrical characteristics with respect to micro-channel size were obtained. The results of this research would be greatly helpful to micro-machining and laser engineering community to have helpful guidelines about the oversizing/undersizing expected to be appeared in microchannel geometry for a wide range of micro-channel sizes.

\section{Experimental Setup}

Micro-channels of different sizes were produced in titanium alloy (Ti-6Al-4V) using 30W Q-switched Nd:YAG pulsed laser irradiating at the workpiece top surface with a constant focal length of $100 \mathrm{~mm}$ and emitting the laser pulses of $10 \mu$ s pulse duration and $1064 \mathrm{~nm}$ wavelength following the Gaussian mode of laser beam. The spot diameter was $20 \mu \mathrm{m}$. Three laser parameters were selected as the variable factors to investigate the influences on micro-channel sizing. The variable factors include lamp current intensity (I), pulse frequency (f) and scan speed (V). The list of fixed laser parameters and variable factors are also shown in table 1 . The screening of laser parameters and their levels were decided with the help of specific guidelines of lasertec 40 system, extensive pilot experimentation and our previous study [32]. The experimental setup is shown in Fig. 1.

Square cross sectional titanium bars $\left(6 \times 6 \mathrm{~mm}^{2}\right)$ of length $25 \mathrm{~mm}$ have been used as prime workpieces. The chemical composition of as received Ti-6Al-4V and its thermos- 
physical properties are shown in table 2 and table 3, respectively. Rectangular cross-sectional micro-channels of different sizes were produced through laser beam micromilling (LBMM). Total of five micro-channel sizes $(100 \times 50$ $\mu \mathrm{m}, 200 \mathrm{x} 100 \mu \mathrm{m}, 400 \times 200 \mu \mathrm{m}, 800 \times 400 \mu \mathrm{m}$ and 1000x500 $\mu \mathrm{m})$ were selected having constant lengths but different widths and depths. Schematic illustration of proposed micro-channels in $3 \mathrm{D}$ CAD model is presented in Fig. 2.
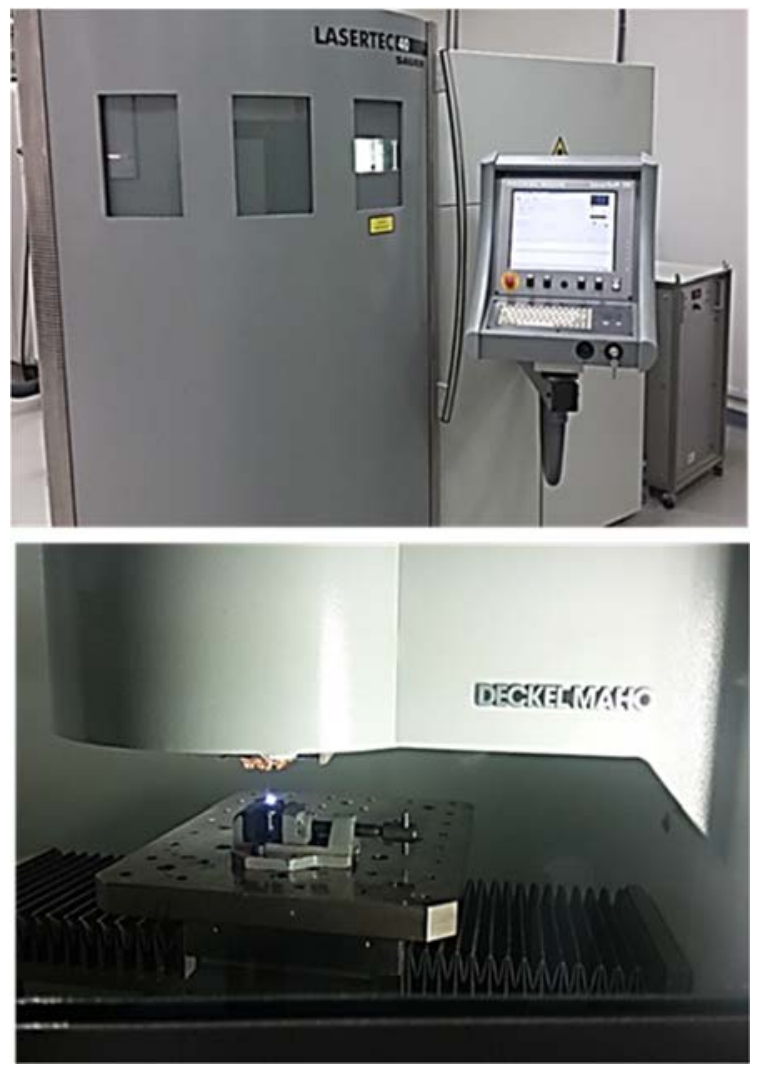

Fig. 1 Experimental setup of Nd:YAG laser beam micromilling (LBMM)
A constant distance of $2 \mathrm{~mm}$ between two successive channels was always maintained just to ensure that each fabricated channel holds its own details and not to mingle the laser effects (thermal effects, melt debris, burrs and spatter etc.) associated with one channel to its neighboring channel. As during laser beam micro-milling (LBMM) the incoming laser beam focuses on the work surface, therefore, more the surface is flat the more uniformity in laser focusing would be. Workpiece of high surface roughness means the focal distance is highly uneven over the work surface. To avoid this primary problem the surface roughness of as received titanium bars were measured by Form Talysurf and recorded an average surface roughness of Ra $3.85 \mu \mathrm{m}$. Therefore, all the specimens were mechanically grinded to bring the surface roughness well below the value that may create severe unevenness during laser focusing. Hence, the finally prepared surface having average roughness of $0.12 \mu \mathrm{m} \mathrm{Ra}$ was used for all the experiments.

\section{Design of Experiments (DOE) Details}

In order to produce the micro-channels in titanium alloy by laser beam micro-milling (LBMM), response surface methodology (RSM) based design of experimental plan was designed. RSM is selected because this method allows to work on relatively more combinations of variable factors with reduced number of experimental runs in its full factorial design and consequently utilization of less resources. Therefore, rather utilizing the fractional factorial designs of other techniques (e.g. Taguchi method), full factorial design of response surface method is employed. Thus, during the design of experiments, the lamp current intensity (x1), pulse frequency (x2) and scan speed (x3) were considered as the controllable laser process parameters to evaluate their effects on four kinds of dimensional characteristics of micro-channels including oversizing and/or undersizing in top width $(\triangle \mathrm{XT})$, bottom width $(\Delta \mathrm{XB})$, depth $(\Delta \mathrm{Z})$ and taperness of sidewalls $(\Theta)$. For the purpose of simplification the range of variable factors were coded as shown in table 4.

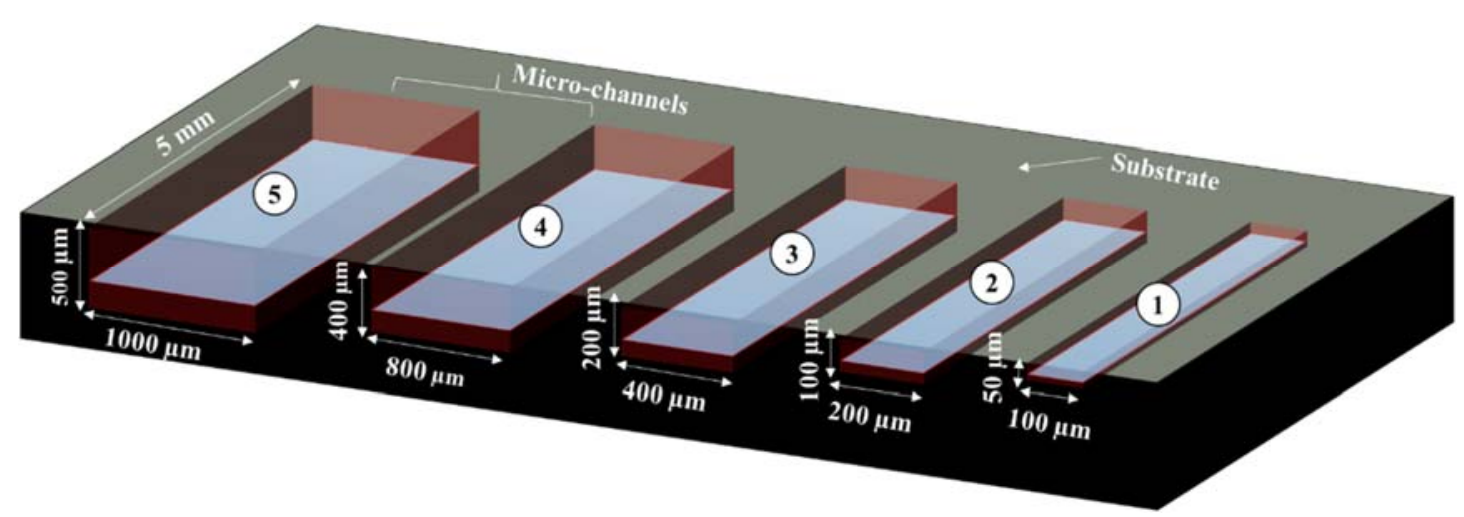

Fig. 2 3D schematic of different sized micro-channels in Ti-6Al-4V (Dimensions are not to scale) 
Table 1 List of laser parameters used in this study

\begin{tabular}{cccc}
\hline \multicolumn{2}{c}{ Fixed Factors } & \multicolumn{2}{c}{ Variable Factors } \\
\hline Factor Name & Fixed Value & Variable Name & Selected Range \\
\hline Laser Type & $\begin{array}{c}\text { Q-Switched } \\
\text { Nd:YAG }\end{array}$ & $\begin{array}{c}\text { Lamp Current } \\
\text { Intensity }(\mathrm{I})\end{array}$ & $82-88 \%$ \\
\hline Wavelength $(\lambda)$ & $1064 \mathrm{~nm}$ & Pulse Frequency $(\mathrm{f})$ & $30-40 \mathrm{kHz}$ \\
\hline Pulse Duration & $10 \mu \mathrm{s}$ & Laser Scan Speed $(\mathrm{V})$ & $300-400 \mathrm{~mm} / \mathrm{s}$ \\
\hline Beam Diameter $(\phi)$ & $20 \mu \mathrm{m}$ & - & - \\
\hline Scan Direction $(\mathrm{X})$ & Random & - & - \\
\hline Feed Rate $(\mathrm{FR})$ & $2 \mu \mathrm{m} / \mathrm{laser}$ pass & - & - \\
\hline Scanning Track & $10 \mu \mathrm{m}$ & - & - \\
Displacement $(\mathrm{D})$ & - & - & - \\
\hline Focal Length $(\mathrm{FL})$ & $100 \mathrm{~mm}$ & - & \\
\hline Focal Point $(\mathrm{d})$ & On top work & & \\
\hline
\end{tabular}

Table 2 Chemical composition of as received Ti-6Al-4V

\begin{tabular}{cccccccccccc}
\hline \multirow{2}{*}{ Sample Source } & \multirow{2}{*}{ Test facility } & \multicolumn{10}{c}{ Elements (\%) } \\
\cline { 3 - 12 } & & $\mathrm{Al}$ & $\mathrm{V}$ & $\mathrm{Fe}$ & $\mathrm{O}$ & $\mathrm{C}$ & $\mathrm{N}$ & $\mathrm{Y}$ & $\mathrm{Ti}$ & Other \\
\hline \multirow{2}{*}{ Ingot } & ATI-WAHCHANG & 6.11 & 4.0 & 0.18 & 0.18 & 0.01 & 0.01 & $<0.005$ & Balance & 0.40 \\
\hline
\end{tabular}

Table 3 Thermo-physical properties of Ti-6Al-4V [33-37]

\begin{tabular}{|c|c|c|c|c|}
\hline Property & Symbol & Condition & Value & Unit \\
\hline Hardness & $H V_{20}$ & - & 600 & HVN \\
\hline Yield strength & $\delta_{y}$ & - & 745 & $\mathrm{MPa}$ \\
\hline Elastic Modulus & $E$ & - & 110 & $\mathrm{GPa}$ \\
\hline Density & $\rho$ & - & 4.43 & $\mathrm{~g} / \mathrm{cm}^{3}$ \\
\hline Melting temperature & $T_{m}$ & - & $1604-1660$ & ${ }^{\circ} \mathrm{C}$ \\
\hline $\begin{array}{l}\text { Coefficient of thermal } \\
\text { expansion }\end{array}$ & $\alpha$ & $20-500^{\circ} \mathrm{C}$ & $8.6-9.7$ & $\mu \mathrm{m} / \mathrm{m}{ }^{\circ} \mathrm{C}$ \\
\hline Specific heat capacity & $C p$ & $C_{p}=0.176 . T+540$ & $\begin{array}{c}T \leq T_{m}: \\
C_{p}=830.4\end{array}$ & $\mathrm{~J} / \mathrm{kg}{ }^{\circ} \mathrm{C}$ \\
\hline Thermal conductivity & K & $K=0.0156 . T+7$ & $\begin{array}{c}T \leq T_{m}: \\
K=32.74\end{array}$ & $\mathrm{~W} / \mathrm{m}^{\circ} \mathrm{C}$ \\
\hline Latent heat & $L$ & - & 418.680 & $\mathrm{KJ} / \mathrm{Kg}$ \\
\hline Dynamic viscosity & $\mu$ & - & $5.20 \times 10^{-3}$ & $\mathrm{~N} \mathrm{~s} / \mathrm{m}^{2}$ \\
\hline Emissivity & $\varepsilon$ & $\begin{aligned} & 132-760{ }^{\circ} \mathrm{C} \\
> & 760-1100^{\circ} \mathrm{C}\end{aligned}$ & $\begin{array}{c}0.22-0.3 \\
0.7-0.98\end{array}$ & - \\
\hline $\begin{array}{c}\text { Absorptivity@ } 10.64 \\
\mu \mathrm{m} \text { wavelength }\end{array}$ & $A$ & $\begin{array}{l}500-1400{ }^{\circ} \mathrm{C} \\
928^{\circ} \mathrm{C}\end{array}$ & $\begin{array}{l}0.28-0.41[35] \\
0.38[37]\end{array}$ & - \\
\hline
\end{tabular}

It should be noted that there were five different sizes of micro-channels $(100 \times 50 \mu \mathrm{m}, 200 \times 100 \mu \mathrm{m}, 400 \times 200 \mu \mathrm{m}$, $800 \times 400 \mu \mathrm{m}$ and $1000 \times 500 \mu \mathrm{m})$ and four geometrical measurements (top width, bottom width, depth and degree of taperness) for ach micro-channel size. The difference between each geometrical dimension (actual) from designed dimension was recoded and afterwards variation from designed dimension was calculated (explanation is provided in next section). In this way, four kinds of variations were calculated corresponding to four geometrical characteristics named as variations in top width $(\triangle \mathrm{XT})$, bottom width $(\triangle \mathrm{XB})$, depth $(\Delta \mathrm{Z})$ and taperness of sidewalls $(\Theta)$. Hence, these four variations were considered as the LBMM process performance measures (responses). Details are summarized in table 5. 
JLMN-Journal of Laser Micro/Nanoengineering Vol. 11, No. 2, 2016

Table 4 Variable factors, actual setting values and coded levels

\begin{tabular}{ccccccc}
\hline $\begin{array}{c}\text { Sr. } \\
\text { No }\end{array}$ & $\begin{array}{c}\text { Machining } \\
\text { Parameters }\end{array}$ & Symbol & Units & \multicolumn{3}{c}{ Coded Level } \\
\cline { 5 - 7 } 1 & $\begin{array}{c}\text { Lamp current } \\
\text { intensity (I) }\end{array}$ & $x_{1}$ & $\mathrm{~A} \mathrm{( \% )}$ & 82 & 85 & 88 \\
\hline 2 & $\begin{array}{c}\text { Pulse frequency } \\
\text { (f) }\end{array}$ & $x_{2}$ & $\mathrm{kHz}$ & 30 & 35 & 40 \\
\hline 3 & $\begin{array}{c}\text { Scanning speed } \\
\text { (V) }\end{array}$ & $x_{3}$ & $\mathrm{~mm} / \mathrm{s}$ & 300 & 350 & 400 \\
\hline
\end{tabular}

Table 5 Details of Micro-channels; shape, dimensions, symbols and sizes

\begin{tabular}{|c|c|c|c|c|c|c|c|c|c|}
\hline Material & $\begin{array}{l}\text { Micro- } \\
\text { feature }\end{array}$ & $\begin{array}{c}\text { Dimension } \\
\text { Details }\end{array}$ & $\begin{array}{c}\text { Response } \\
\text { Names }\end{array}$ & $\begin{array}{l}\text { Common } \\
\text { Symbols }\end{array}$ & & ailed Siz & and $R e$ & onse $\mathbf{S y}$ & bols \\
\hline \multirow{13}{*}{$\begin{array}{c}\text { Ti-6Al- } \\
4 \mathrm{~V}\end{array}$} & \multirow{13}{*}{$\begin{array}{c}\text { Rectangular } \\
\text { Cross } \\
\text { Section } \\
\text { Micro- } \\
\text { channels }\end{array}$} & $\begin{array}{l}\text { Micro- } \\
\text { channel } \\
\text { Notation }\end{array}$ & - & - & 1 & 2 & 4 & 8 & 10 \\
\hline & & \multirow{4}{*}{$\begin{array}{c}\text { Designed } \\
\text { Dimensions }\end{array}$} & $\begin{array}{c}\text { Top } \\
\text { Width }\end{array}$ & DXT & 100 & 200 & 400 & 800 & 1000 \\
\hline & & & $\begin{array}{l}\text { Bottom } \\
\text { Width }\end{array}$ & DXB & 100 & 200 & 400 & 800 & 1000 \\
\hline & & & Depth & DZ & 50 & 100 & 200 & 400 & 500 \\
\hline & & & Taper & $\mathrm{DO}$ & 0 & 0 & 0 & 0 & 0 \\
\hline & & \multirow{4}{*}{$\begin{array}{c}\text { Actual } \\
\text { Dimensions }\end{array}$} & $\begin{array}{c}\text { Top } \\
\text { Width }\end{array}$ & AXT & AXT-1 & AXT-2 & AXT-4 & AXT-8 & AXT-10 \\
\hline & & & $\begin{array}{l}\text { Bottom } \\
\text { Width }\end{array}$ & $\mathrm{AXB}$ & AXB-1 & $\begin{array}{c}\text { AXB- } \\
2\end{array}$ & AXB-4 & AXB-8 & AXB-10 \\
\hline & & & Depth & $\mathrm{AZ}$ & AZ-1 & AZ-2 & AZ-4 & AZ-8 & AZ-10 \\
\hline & & & Taper & $\mathrm{A} \Theta$ & $\mathrm{A} \Theta-1$ & $\mathrm{~A} \Theta-2$ & $\mathrm{A \Theta}-4$ & AӨ-8 & $\mathrm{A \Theta}-10$ \\
\hline & & \multirow{4}{*}{$\begin{array}{l}\text { Variation in } \\
\text { Dimensions } \\
\text { (Responses) }\end{array}$} & $\begin{array}{c}\text { Top } \\
\text { Width }\end{array}$ & $\Delta \mathrm{XT}$ & $\Delta \mathrm{XT}-1$ & $\Delta \mathrm{XT}-2$ & $\Delta \mathrm{XT}-4$ & $\Delta \mathrm{XT}-8$ & $\Delta \mathrm{XT}-10$ \\
\hline & & & $\begin{array}{l}\text { Bottom } \\
\text { Width }\end{array}$ & $\Delta \mathrm{XB}$ & $\Delta \mathrm{XB}-1$ & $\Delta \mathrm{XB}-2$ & $\Delta \mathrm{XB}-4$ & $\Delta \mathrm{XB}-8$ & $\Delta \mathrm{XB}-10$ \\
\hline & & & Depth & $\Delta \mathrm{Z}$ & $\Delta \mathrm{Z}-1$ & $\Delta Z-2$ & $\Delta \mathrm{Z}-4$ & $\Delta \mathrm{Z}-8$ & $\Delta \mathrm{Z}-10$ \\
\hline & & & Taper & $\Delta \Theta$ & $\Delta \Theta-1$ & $\Delta \Theta-2$ & $\Delta \Theta-4$ & $\Delta \Theta-8$ & $\Delta \Theta-10$ \\
\hline
\end{tabular}

Table 6 Details of full factorial RSM based face centered central composite design (FCCCD)

\begin{tabular}{cccccccccc}
\hline $\begin{array}{c}\text { Design } \\
\text { Method }\end{array}$ & Factors & Levels & Blocks & A & $\begin{array}{c}\text { Cube } \\
\text { points }\end{array}$ & $\begin{array}{c}\text { Center } \\
\text { points } \\
\text { in cube }\end{array}$ & $\begin{array}{c}\text { Axial } \\
\text { points }\end{array}$ & $\begin{array}{c}\text { Center } \\
\text { points } \\
\text { in axial }\end{array}$ & Runs \\
\hline $\begin{array}{c}\text { RSM Full } \\
\text { Factorial }\end{array}$ & 3 & 3 & 2 & 1 & 8 & 4 & 6 & 2 & 20 \\
\hline
\end{tabular}

Full factorial face cantered central composite design (FCCCD) was utilized. A central composite design consists of a "cube" portion made up of design points from a $2^{\mathrm{k}}$ factorial or $2^{\mathrm{k}-1}$ fractional factorial design; $2 \mathrm{~K}$ axial or "star" points and center points (where $\mathrm{K}$ is the number of factors). Here in our case, $\mathrm{K}=3$. According to this FCCCD design, there were 8 cube points, 6 axial, 4 center points in cube and 2 center points in axial (as the design is face centered central composite design). Another important consideration for CCD experimental design is the selection of appropriate $\alpha$-value. This value indicates the distance of the axial points from the design center in a central composite design and is expressed in coded units. A value less than one places the axial points inside the cube; a value equal to one places them on the faces of the cube; and a value greater than one places them outside the cube. As our design was FCCCD and the center points on axial were kept on the cube space, therefore, $\alpha=1$ was selected. The detail of full factorial RSM based FCCCD is presented in table 
6. In this way 20 number of experimental runs were suggested by the design for above said conditions. The full experimental plan has been shown in table 7 . The same plan was repeated while laser processing of each of the five micro-channel sizes. In this fashion a total of 100 number of experiments were performed (20 runs per/channel size x 5 channel sizes).

Table 7 Experimental plan for RSM based FCCCD

\begin{tabular}{|c|c|c|c|c|}
\hline \multirow{2}{*}{ RunOrder } & \multirow{2}{*}{ Blocks } & \multirow{2}{*}{$\begin{array}{c}\mathbf{I} \\
\mathbf{x 1}\end{array}$} & \multirow{2}{*}{$\begin{array}{c}\mathbf{F} \\
\mathbf{x} 2\end{array}$} & \multirow{2}{*}{$\begin{array}{c}\mathbf{V} \\
\mathbf{x 3} \\
\end{array}$} \\
\hline & & & & \\
\hline 1 & 1 & -1 & 1 & 1 \\
\hline 2 & 1 & 0 & 0 & 0 \\
\hline 3 & 1 & -1 & -1 & -1 \\
\hline 4 & 1 & 0 & 0 & 0 \\
\hline 5 & 1 & 1 & -1 & -1 \\
\hline 6 & 1 & -1 & -1 & 1 \\
\hline 7 & 1 & 0 & 0 & 0 \\
\hline 8 & 1 & 1 & -1 & 1 \\
\hline 9 & 1 & 1 & 1 & 1 \\
\hline 10 & 1 & 1 & 1 & -1 \\
\hline 11 & 1 & 0 & 0 & 0 \\
\hline 12 & 1 & -1 & 1 & -1 \\
\hline 13 & 2 & 0 & 0 & 0 \\
\hline 14 & 2 & 1 & 0 & 0 \\
\hline 15 & 2 & 0 & 1 & 0 \\
\hline 16 & 2 & -1 & 0 & 0 \\
\hline 17 & 2 & 0 & -1 & 0 \\
\hline 18 & 2 & 0 & 0 & -1 \\
\hline 19 & 2 & 0 & 0 & 1 \\
\hline 20 & 2 & 0 & 0 & 0 \\
\hline
\end{tabular}

\section{Results and Discussions}

After fabricating the designed number of channels per size, the optical microscopic images of all the channels were organized to record the actual experimental results (geometrical characteristics). The main effects plots of investigated laser parameters were designed to study the behaviour of each geometrical dimension over each individual laser parameter. Detailed descriptions of geometrical measurements and parametric influences are furnished in the subsequent sections.

\subsection{Geometrical Measurements}

All the test samples (after producing micro-channels) were cross-sectioned and hot mounted in resin (heating and cooling cycles of 4 and 6 minutes, respectively). Later on, the progressive grinding was performed just to remove the secondary cutting process striation marks and mounting residuals. Each sample was observed under optical microscope and geometrical measurements were very carefully measured. The schematic diagram as shown in Fig. 3 depicts what different geometrical characteristics were under study and how they were measured. Figure 3 (a) shows the 2D schematic of micro-channel with reasonable bottom width (flat bottom) while Fig. 3 (b) is about the micro-channel with conical bottom having zero bottom width as some of the resulted microchannels were nearly conical in shape with zero bottom width.

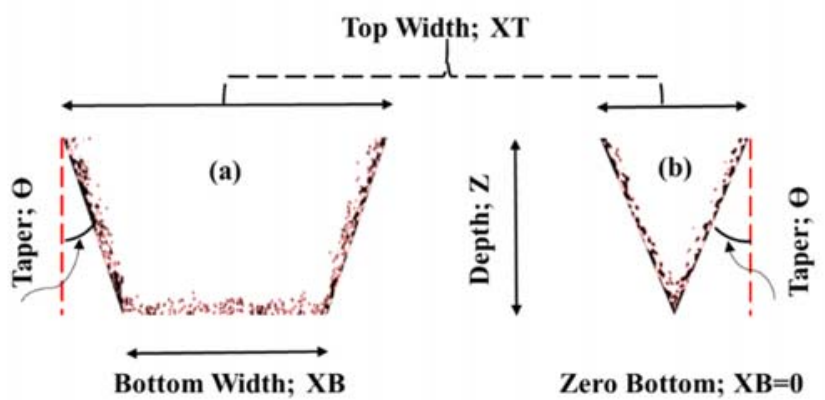

Fig. 3 Schematic diagram of geometrical measurements such as top width (XT), bottom width (XB), depth (Z) and sidewall taper $(\Theta)$; (a) flat bottom (b) zero bottom

Following the schematic of Fig. 3, the input geometrical dimensions of micro-channels to laser CNC program (as designed and shown in Fig. 2) were symbolized as designed dimensions (refer to table 5), e.g. designed top width (DXT), designed bottom width (DXB), designed depth (DZ) and designed taperness (DӨ). Likewise, experimentally observed geometrical characteristics were termed as actual geometrical characteristics such as actual top width (AXT), actual bottom width (AXB), actual depth (AZ) and actual taperness (AO). Thereafter, the variation in each of the micro-channel dimension (responses as mentioned in table 5) was then calculated by utilizing equations (1), (2), (3) and (4), where, $\triangle \mathrm{XT}$ is the variation in top width, $\triangle \mathrm{XB}$ indicates the variation in bottom width, $\Delta \mathrm{Z}$ represents the variation in depth and $\Delta \Theta$ stands for the variation in degree of taperness.

$$
\begin{gathered}
\Delta X T=\{(A X T / D X T)-1\} \times 100 \\
\Delta X B=\{(A X B / D X B)-1\} \times 100 \\
\Delta Z=\{(A Z / D Z)-1\} \times 100 \\
\theta=\operatorname{Tan}^{-1}[\{(A X T-A X B) /(2 \times A Z)\} \\
\quad \times(180 / \pi)]
\end{gathered}
$$


These generalized variations are linked with each individual micro-channel size. For instance, the generalized variation in top width is $\triangle \mathrm{XT}$ and the individual variations in individual micro-channel sizes of $100 \times 50 \mu \mathrm{m}, 200 \times 100 \mu \mathrm{m}$, $400 \times 200 \mu \mathrm{m}, 800 \times 400 \mu \mathrm{m}$ and $1000 \times 500 \mu \mathrm{m}$ have been symbolized as $\Delta \mathrm{XT}-1, \Delta \mathrm{XT}-2, \Delta \mathrm{XT}-4, \Delta \mathrm{XT}-8$, and $\Delta \mathrm{XT}-10$, respectively. Similar pattern has been opted for the other geometrical characteristics such as $\triangle \mathrm{XB}-1, \Delta \mathrm{XB}-2, \ldots \Delta \mathrm{XB}-$ 10 and $\Delta \mathrm{Z}-1, \Delta \mathrm{Z}-2, \ldots \Delta \mathrm{Z}-10$ and similarly $\Delta \Theta-1, \Delta \Theta-2 \ldots$ $\Delta \Theta-10$. These notations and symbols are, however, categorically tabulated in table 5. The objective of this research is to study the variation (in terms of oversizing and undersizing) of four geometrical characteristics among different sizes, that's why the response indicators are symbolized as $\Delta \mathrm{XT}, \Delta \mathrm{XB}, \Delta \mathrm{Z}$ and $\Delta \Theta$.

Although, the nanosecond and femtosecond lasers are generally used for laser micro-machining, however, in this research Nd:YAG laser having $10 \mu$ s pulse duration is used to evaluate the process performance during micro-machining of various sized micro-channels. It is found that the microchannels of large sizes $(400 \times 200 \mu \mathrm{m}, 800 \times 400 \mu \mathrm{m}$ and $1000 \times 500 \mu \mathrm{m})$ can be more precisely machined through $\mathrm{Nd}$ :YAG laser of micro-second pulse duration. The selected microphotographs of each of the micro-channel size $(100 \times 50$ $\mu \mathrm{m}, 200 \times 100 \mu \mathrm{m}, 400 \times 200 \mu \mathrm{m}, 800 \times 400 \mu \mathrm{m}$ and 1000x500 $\mu \mathrm{m})$ are shown in figures 4-8. Four microphotographs are randomly selected and combined so that each figure can convey a brief picture of the actual shapes and sizes of the fabricated channels in titanium alloy (Ti-6Al-4V) produced through Nd:YAG pulsed laser beam micro-milling (LBMM). The laser parameters employed to produce the micro-channel are labelled on each of the microphotograph. The microscopic images of each of the micro-channel size are randomly selected against different laser parameters. The objective is to show the geometrical effects of laser parameters from a wide range of parametric combinations. Each of the parametric combinations produces different geometries. Figure 4 shows the actual micro-channels generated against the designed size of $100 \times 50 \mu \mathrm{m}$. It can be observed that there is not just a difference in micro-channel sizes but also in shapes. Similarly, Fig. 5 represents the actual results of micro-channels of size 200x100 $\mu \mathrm{m}$. The channel produced under lamp current intensity of $85 \%$, pulse frequency of $35 \mathrm{kHz}$ and scan speed of $350 \mathrm{~mm} / \mathrm{s}$ (as shown in (d) of Fig. 5) is close to the designed size with reasonable amount of bottom width. It can be noticed that the presence of taperness is always there for all the microchannels. The channels of size $400 \times 200 \mu \mathrm{m}$ are illustrated in Fig. 6. This size also gives channels with actual dimensions a bit close to the designed dimensions under current intensity, pulse frequency and scan speed of $85 \%, 35 \mathrm{kHz}$ and $350 \mathrm{~mm} / \mathrm{s}$, respectively. In a similar fashion, the micro-channels of sizes 800x400 $\mu \mathrm{m}$ and 1000x500 $\mu \mathrm{m}$ can be seen in Fig. 7 and Fig. 8 , respectively. It can be interestingly noticed that the every channel produced against the designed size $\geq 400 \times 200 \mu \mathrm{m}$, the chances of getting zero bottom width are very less as the laser beam has to travel ample of distance along $\mathrm{x}$-direction (widthwise direction) and the result is a micro-channel with significant bottom width and close to rectangular cross section.
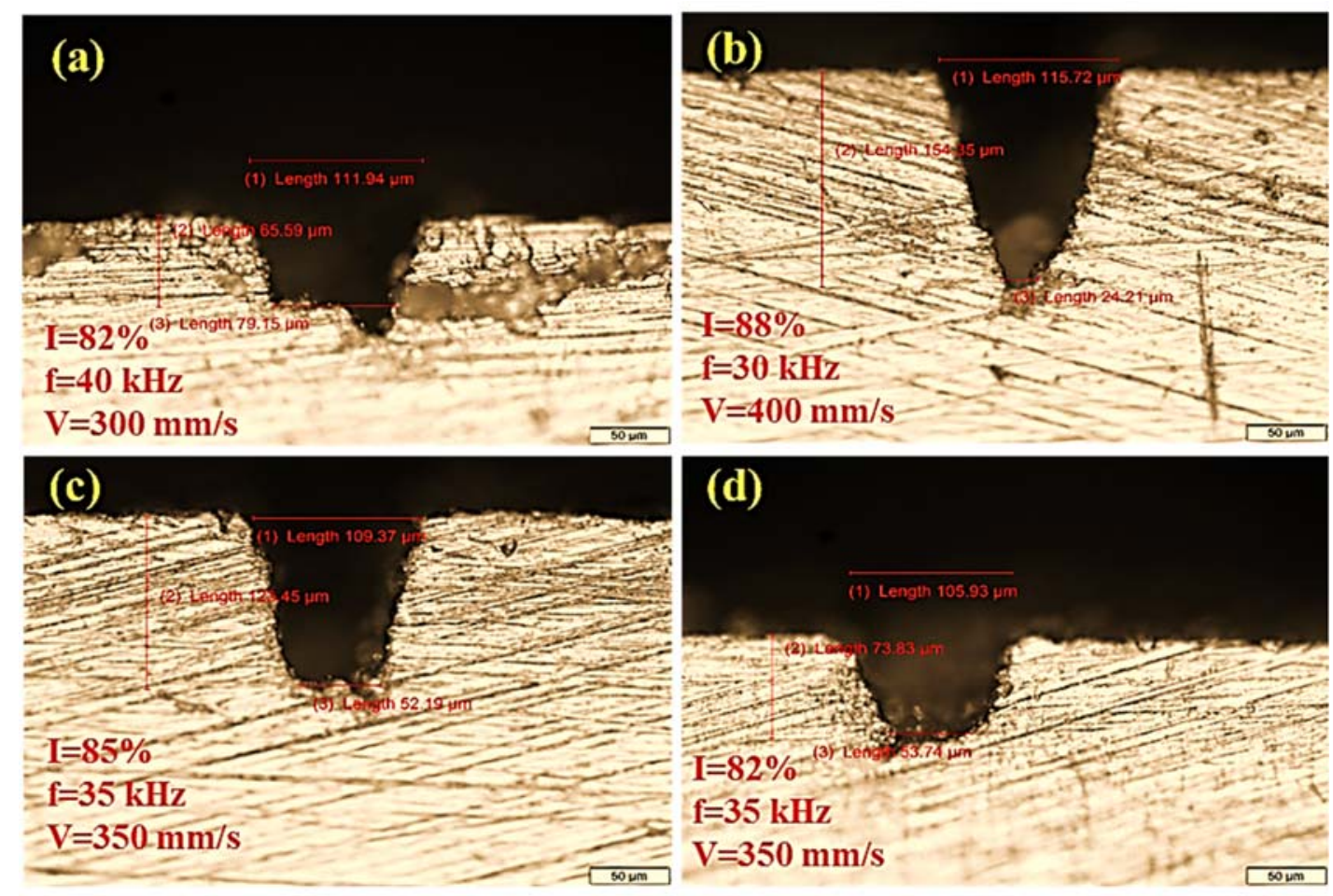

Fig. 4 Micro-channels of input size 100x50 $\mu \mathrm{m}$ fabricated under different laser parameters as labelled on each of (a), (b), (c) and (d) 

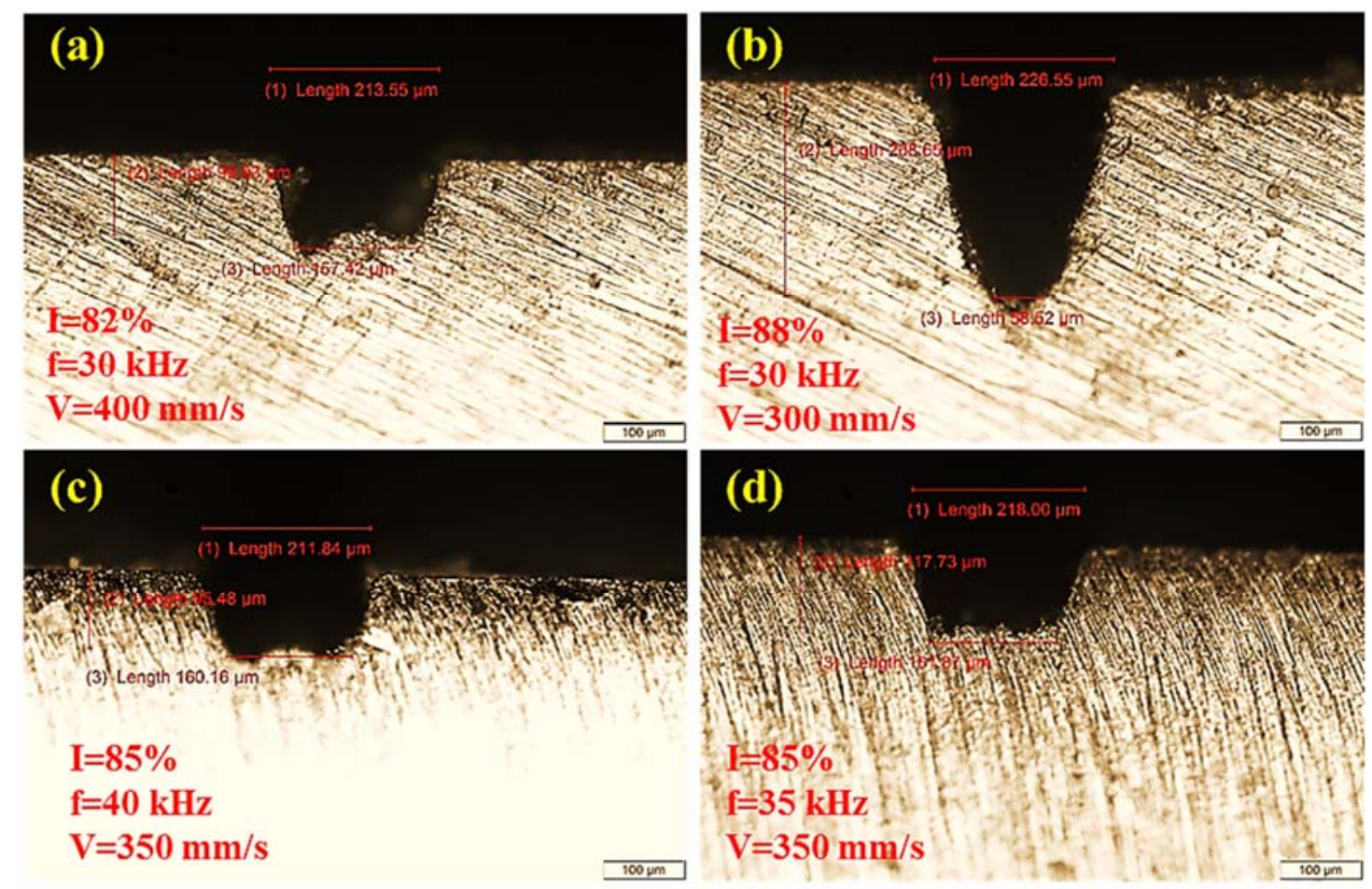

Fig. 5 Micro-channels of input size 200x100 $\mu \mathrm{m}$ fabricated under different laser parameters as labelled on each of (a), (b), (c) and (d)
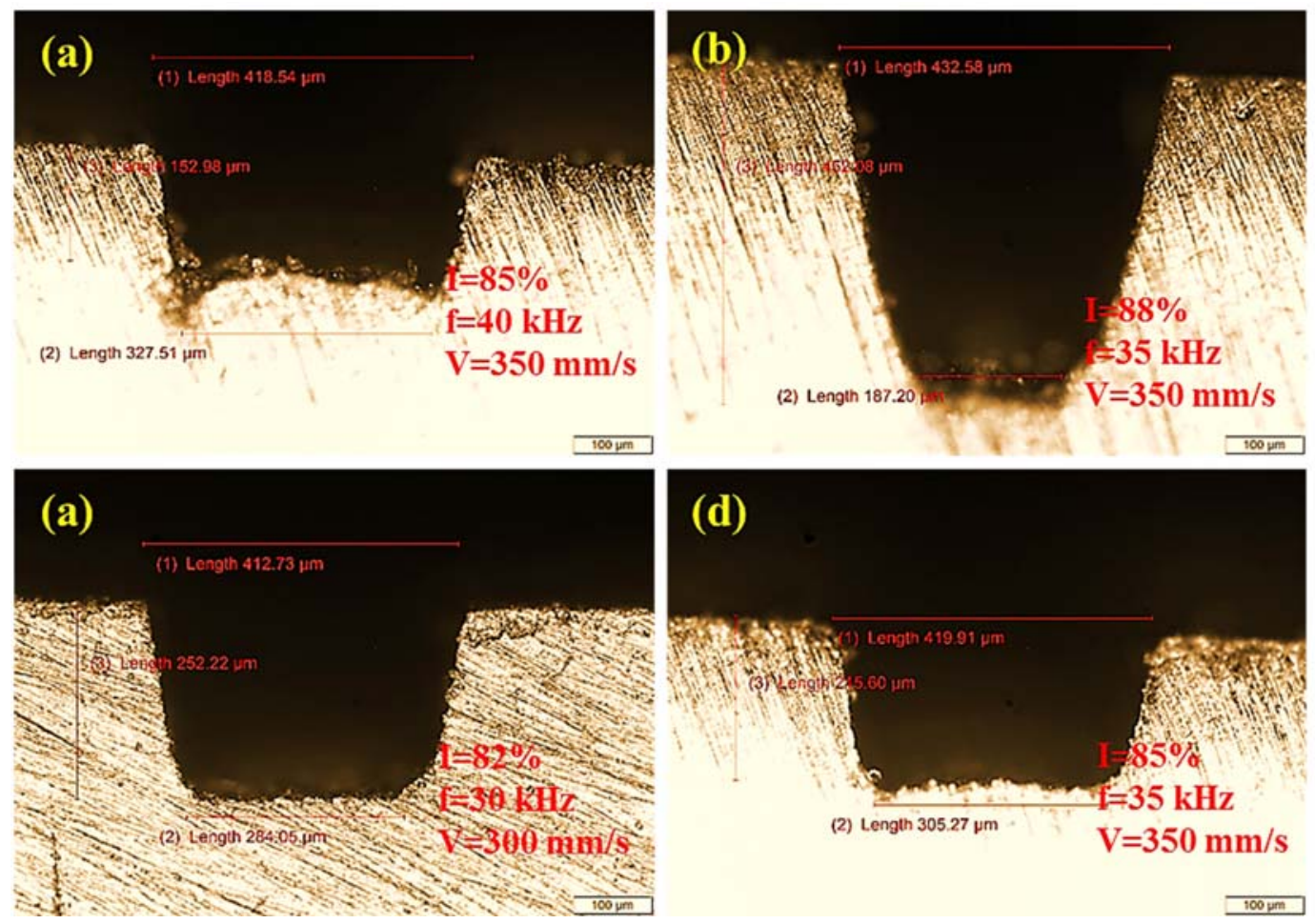

Fig. 6 Micro-channels of input cross sectional size $400 \times 200 \mu \mathrm{m}$ fabricated under different laser parameters as labelled on each of (a), (b), (c) and (d) 

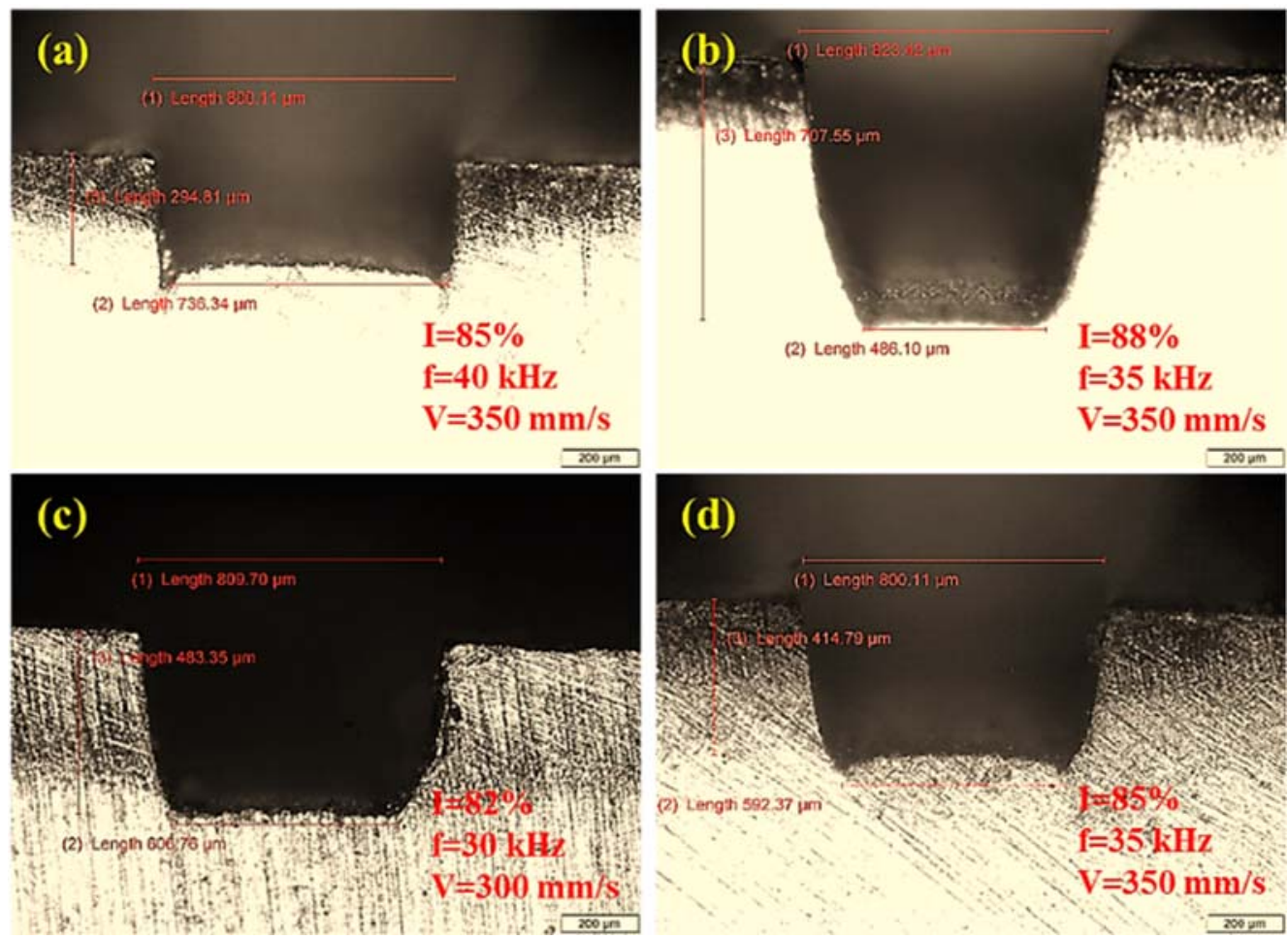

Fig. 7 Micro-channels of input cross sectional size $800 \times 400 \mu \mathrm{m}$ fabricated under different laser parameters as labelled on each of (a), (b), (c) and (d)
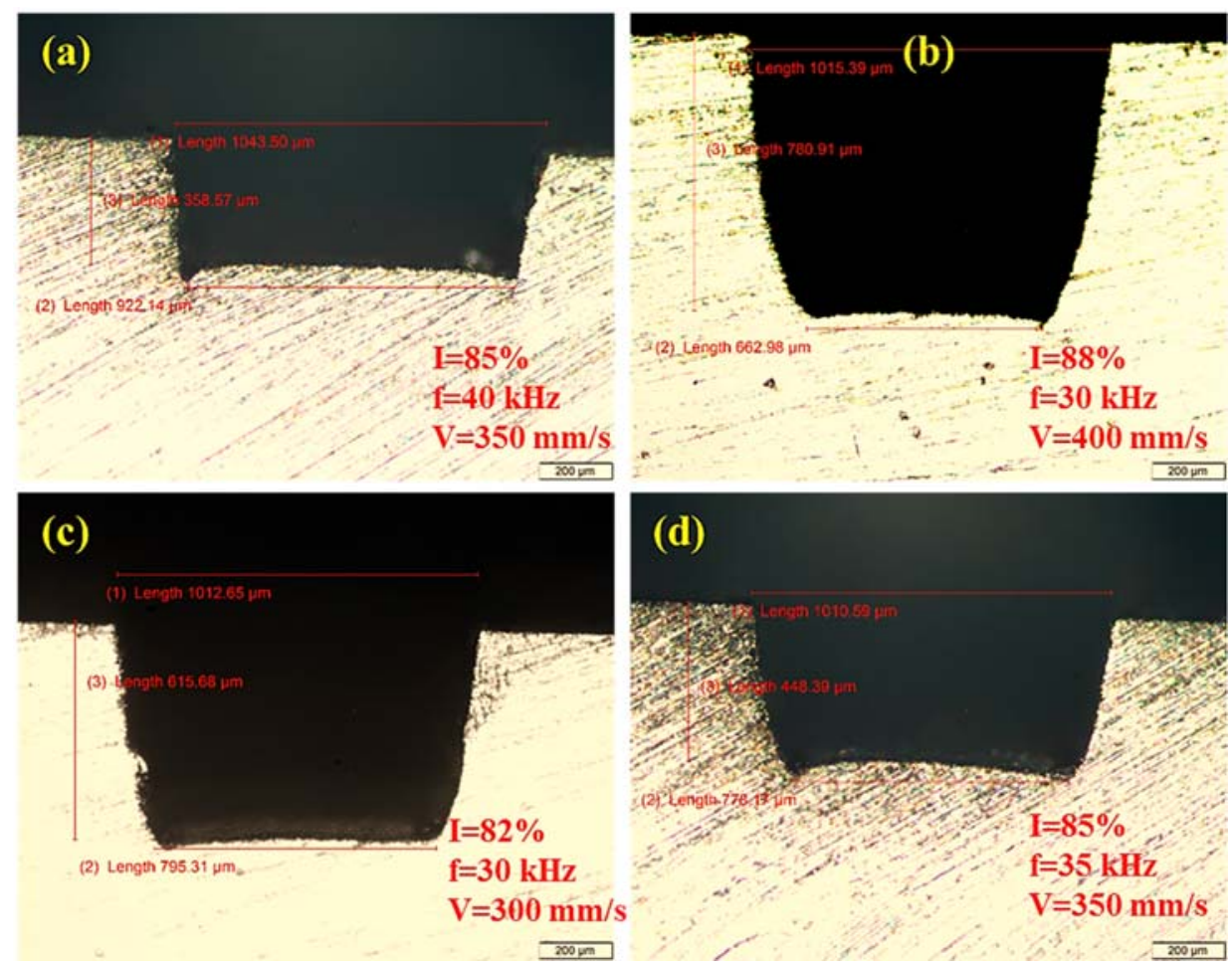

Fig. 8 Micro-channels of input cross sectional size 1000x500 $\mu \mathrm{m}$ fabricated under different laser parameters as labelled on each of (a), (b), (c) and (d) 


\subsection{Dimensional Variation in Top Width $(\Delta X T)$}

Variation or oversizing in each geometrical characteristics associated with each micro-channel size was calculated using equations $1-4$, as described above. Then all the variations were plotted against individual laser parameters employed in this study. Such plots related to variation in top width $(\Delta \mathrm{XT})$ are collectively shown in Fig. 9. It should be noted that the whole variation in top width is positive which means that there is oversizing in this dimensional characteristic of microchannel geometry. The variation with negative sign (as in case of bottom width $\triangle \mathrm{XB}$ ) will indicate the undersizing in that specific geometrical characteristic. It should be noted that the plots shown in Fig. 9 (as well as in figures 10-12) are individually prepared to evaluate the effects of laser parameters and afterwards the plots are clubbed in one figure to build an easy understanding. In each of the parametric effects, the actual machining data is plotted against each laser parameter while keeping the other two variables at constant levels.

\subsubsection{Effect of Lamp Current Intensity}

Figure 9 (a) shows the plot between variations in top width of different sized micro-channels produced in Ti-6Al$4 \mathrm{~V}$ against laser lamp current intensity (x1). As the lamp current intensity increases the top width of micro-channels also increases irrespective to the channel size. Increase in current intensity means an increase in power and resultantly increase in pulse peak power. Laser energy per unit area increases as a result of which more material removal occurs per laser spot and consequently channel becomes wider than the designed input value. The coefficient of thermal expansion also play a role in widening the channel opening. For titanium alloy Ti-6Al-4V, the coefficient of thermal expansion is $8.6-$ $9.7 \mu \mathrm{m} / \mathrm{m}{ }^{\circ} \mathrm{C}$ when the temperature ranges within $20-500{ }^{\circ} \mathrm{C}$. At further elevated temperature the expansion becomes more. Likewise, thermal conductivity of Ti-6Al-4V increases with an increase in temperature. As the temperature increases from 25 to $1650{ }^{\circ} \mathrm{C}$ (just close to melting temperature of Ti-6Al-4V i.e. $1660{ }^{\circ} \mathrm{C}$ [33]) the corresponding thermal conductivity increases from 7.0 to $28.4 \mathrm{~W} / \mathrm{mK}$ (refer to table 3) [35]. Thus, for smaller sized channels, which already have high concentration of heat, the thermal expansion may also contribute in oversizing the top width (a free end to expand). It is also evident from the graph that the variation in top width of micro-channels $100 \times 50 \mu \mathrm{m}(\Delta \mathrm{XT}-1)$ is far greater than the variation in other micro-channel sizes. In this size, the top widths are oversized within $12-25 \%$ of the designed top width (DXT). As the channel size is small, the thermal energy produced by irradiated laser spot has to be transferred immediate to the edges of the channel. When the laser is scanning in between the channel boundaries, due to confined space available for energy dissipation the heat transfers to the opposite directions and causes the excessive material removal. Additionally, the melt debris also carries significant heat which also piles up due to confined space and widens the channel opening. Contrary to this the oversizing in top widths of micro-channels of sizes $\geq 400 \times 200 \mu \mathrm{m}$ is just below $5 \%$ irrespective to the level of laser lamp current intensity. As the channel sizes increases the laser beam travelling distance along the width direction also increases as of result of which no accumulation of heat occurs at the edges. Hence, the oversizing in top width reaches to its minimum as can be seen the curves of $\Delta X T-8$ and $\Delta X T-10$ in Fig. 9 (a), even no effect of current intensity. Thus, it can be inferred that in general the lowest level of current intensity is more suitable to have lowest oversizing in top widths if the objective is to produce any size of channel especially small sized micro-channels.

\subsubsection{Effects of Pulse Frequency}

The effects of pulse frequency on top widths of micro-channels are depicted in plot (b) of Fig. 9. Irrespective to the level of pulse frequency employed in this study, the variation in top widths of channels $100 \times 50 \mu \mathrm{m}$ and $200 \times 100$ $\mu \mathrm{m}$ i.e. $\Delta \mathrm{XT}-1$ and $\Delta \mathrm{XT}-2$ is greater than the variations in other large sizes (variations are $15-18 \%$ and $7-8 \%$, respectively). The main reason behind this is very nearly same as discussed for current intensity i.e. the narrowed space available to accommodate the pulse energy. Increase in pulse frequency increases the energy per unit area and causes more melting at the edges leading to oversize the top width for all the micro-channel sizes especially wider sized micro-channels. The variation is not very high for wider sized micro-channels. However, in general, the pulse frequency of $35 \mathrm{kHz}$ seems to be better to have relatively less amount of top width variation for all the investigated micro-channel sizes especially narrow sized channels.

\subsubsection{Effects of Scan Speed}

The effects of laser scan speed on sizing of top width are depicted in plot (c) of Fig. 9. The levels of scan speed do not significantly affect the channel opening especially the channels $\geq 200 \times 100 \mu \mathrm{m}$. With respect to the various channel sizes produced in this study the oversizing in top width reduces as the channel sizes increases. For example, the oversizing in top width of $100 \times 50 \mu \mathrm{m}(\triangle \mathrm{XT}-1)$ is $17 \%$ whereas the oversizing in top width of $1000 \times 500 \mu \mathrm{m}$ channel $(\Delta \mathrm{XT}-10)$ is just $1-2 \%$. Hence, it can be stated that the oversizing in top width depends on the channel size whatsoever the scan speed is employed. In a collective way, the variations in top widths of all the fabricated channels are also plotted against the full set of run order obtained through RSM design of experiment (plot (d) of Fig. 9). The previously drawn inferences can also be related to this comparison. It is clear from the graph that the oversizing in top width is less as the channel size is large for all the laser parametric combinations as generated under RSM design of experimental plan.

\subsection{Dimensional Variation in Bottom Width $(\Delta \mathrm{XB})$}

It is worth noting that the designed bottom widths (DXB) for all the channel sizes were exactly equal to the designed top widths (DXT) i.e. 100, 200, 400, 800 and 1000 $\mu \mathrm{m}$. There was a huge difference in actual bottom widths (AXBs) of micro-channels as already evidenced in optical microscopic images (figures 3-8). 

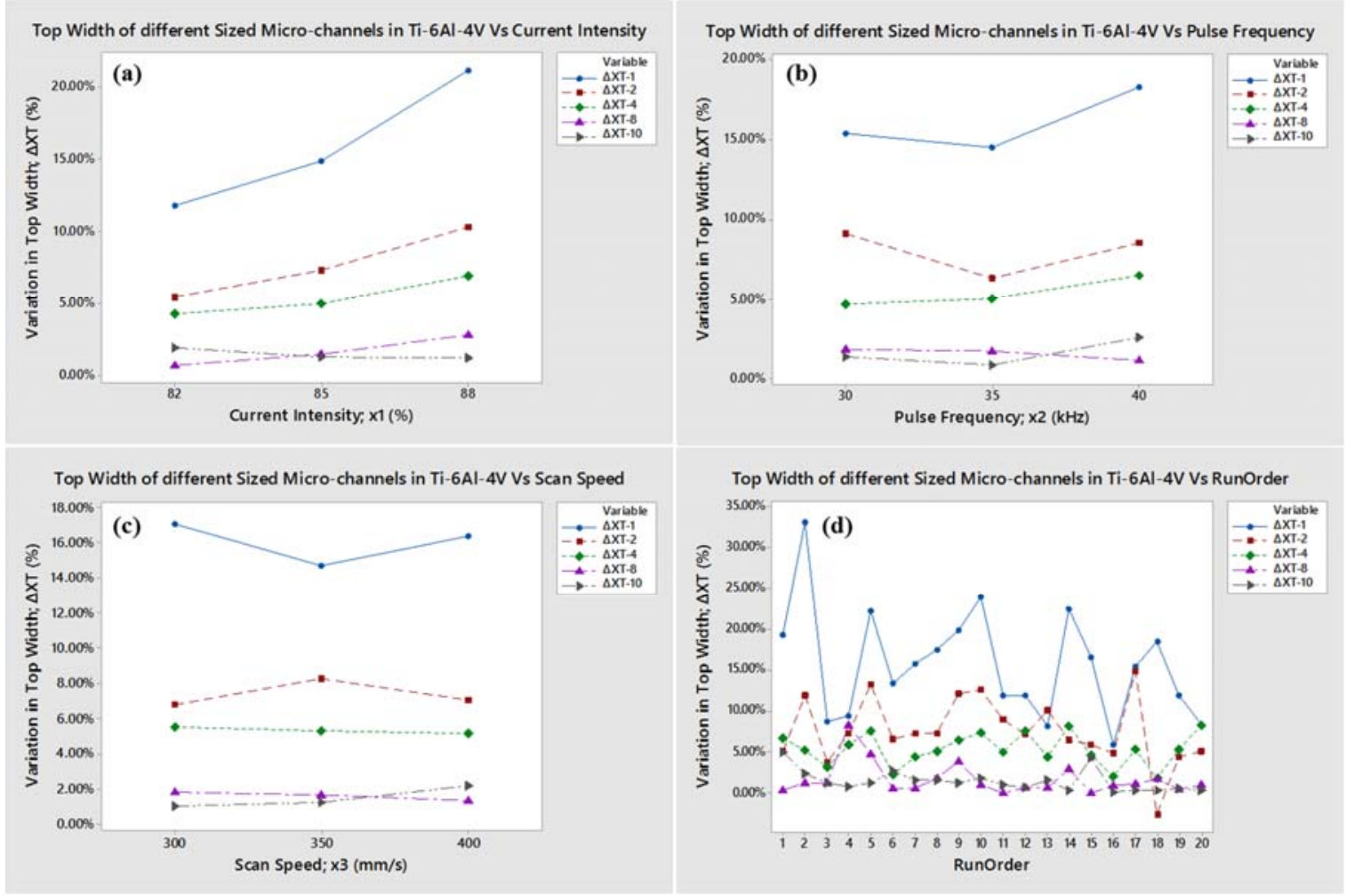

Fig. 9 Variation in top width $(\Delta \mathrm{XT})$ of different sized micro-channels Vs; (a) lamp current intensity, (b) pulse frequency, (c) scan speed and (d) run order.

It is a common phenomenon of laser machining that it imparts some taper as the machining depth progresses. Due to this reason none of the actual bottom widths (AXBs) were achieved close to the designed widths (DXBs). The bottom width was always undersized. That's why the variation in bottom width $(\triangle \mathrm{XB})$ is described in \% variation with negative sign. The negative sign indicates undersizing in the dimension. Thus, higher percentage value with negative sign will translate high amount of variation. For example, $\Delta \mathrm{XB}=-60 \%$ and $\Delta \mathrm{XB}$ $=-10 \%$ means that the width is highly undersized for the first case and less amount of undersizing for the former case. Less undersizing leads the channel profile towards trapezoidal like shape while high amount of undersizing generates conical like shape. It can also be visualized in schematic of Fig. 3 (a) and (b), respectively.

\subsubsection{Effect of Lamp Current Intensity}

Variations in bottom widths $(\triangle \mathrm{XB}) \mathrm{Vs}$ lamp current intensity (x1) are shown in plot (a) of Fig. 10. As the laser current intensity increases the corresponding size of bottom width decreases and consequently the variation from designed value of bottom width also increases. The lowest level of utilized current intensity ( $82 \%$ ) generates reasonable amount of bottom widths for all the micro-channels sizes obtained through laser beam micro-milling (LBMM). The lowest undersizing in bottom widths of channel sizes $\geq 200 \times 100 \mu \mathrm{m}$ ranges within $(-10 \%)-(-20 \%)$ at lowest level of current intensity employed. However, corresponding to this level of current intensity, the bottom width of micro-channel 100x50 $\mu \mathrm{m}(\Delta \mathrm{XB}-1)$ is $50 \%$ of the designed value of bottom width.

\subsubsection{Effects of Pulse Frequency}

The undersizing associated with bottom width in terms of variations plotted against pulse frequency $(\mathrm{x} 2)$ is shown in Fig. 10 (b). Increase in pulse frequency reduces the value of variation in bottom width for all the sizes of microchannels. At each individual level of pulse frequency, there is a progressive pattern in undersizing of bottom widths. For micro-channels of large sizes (e.g. $1000 \times 500 \mu \mathrm{m}$ and $800 \times 400$ $\mu \mathrm{m}$ ), the experimentally obtained widths (AXBs) of bottom side are closer to the designed widths compared to channels of small sizes (i.e. $100 \times 50 \mu \mathrm{m}$ and $200 \times 100 \mu \mathrm{m}$ etc.), leading to infer that there is less amount of undersizing or variation for large micro-channel sizes. The suitable level of pulse frequency could be of $40 \mathrm{kHz}$ if the objective is to attain the reasonable amount of bottom width of micro-channels irrespective to channel size.

\subsubsection{Effects of Scan Speed}

Similarly, the effects of laser scanning speed (x3) on bottom widths are portrayed in plot (c) of Fig. 10. The pattern of this plot resembles closely to the pattern of pulse frequency graph except for channel size 100x50 $\mu \mathrm{m}$. The graphs shows that less is the speed of laser scanning, high is the variation in 
bottom width and vice versa. Low scan speed allows the laser beam to interact with the substrate material for longer period of time compared to interaction time of high scan speed. More interaction time means more laser energy penetrating per laser spot and the result is shallower material removal mark yielding low value of width to depth ratio of material removal. In this way, the resultant width of channel becomes shorter. Higher scan speeds (e.g. $400 \mathrm{~mm} / \mathrm{s}$ ) allow the laser beam to interact for short time interval and thus considered as more favourable to yield less amount of undersizing in bottom widths. The variation in bottom width Vs experimental run order is also plotted just as a reference to speculate the overall trend of micro-channel sizes as shown in plot (d) of Fig. 10. It is clear that irrespective to the parametric combinations corresponding to each run order, the undersizing in bottom widths of large sized micro-channels is relatively less compared to undersizing of small sized micro-channels.

\subsection{Dimensional Variation in Depth $(\Delta Z)$}

In terms of micro-channel depth, the objective was to achieve the actual depth (AZ) close to the designed depth (DZ) with minimum variation. In some cases the actual depths were nearly close to the designed depths but most of the cases there was oversizing in the depth of micro-channel. This variation in depths of micro-channels of different sizes is graphically studied by the plots generated against each investigated laser parameter. The graphical results are illustrated in Fig. 11.

\subsubsection{Effect of Lamp Current Intensity}

The effect of lamp current intensity (x1) on the variation of depth $(\Delta Z)$ of micro-channels are shown in Fig. 11 (a). Increase in current intensity increases the depths of channels irrespective to the micro-channel size. This increase is not highly significant for rise within $82-85 \%$ of maximum current intensity but the effect becomes more significant when current intensity reaches to $88 \%$. Higher the current intensity is the higher the material melting per laser scan is, as result of which, higher depths are achieved. High level of current intensity generates more variation in result of which more oversizing can be observed. The interesting result is that for all the sizes of micro-channels the depth of micro-channel with approximately $0 \%$ variation can be achieved at the lowest level of current intensity except for the case of narrower sized channels $(100 \times 50 \mu \mathrm{m})$ for which the variation in depth is $50 \%$. Hence, the lowest level of current intensity allows the melting of material to be occurred more uniformly over each laser scan and the material is more appropriately removed after each laser pass.
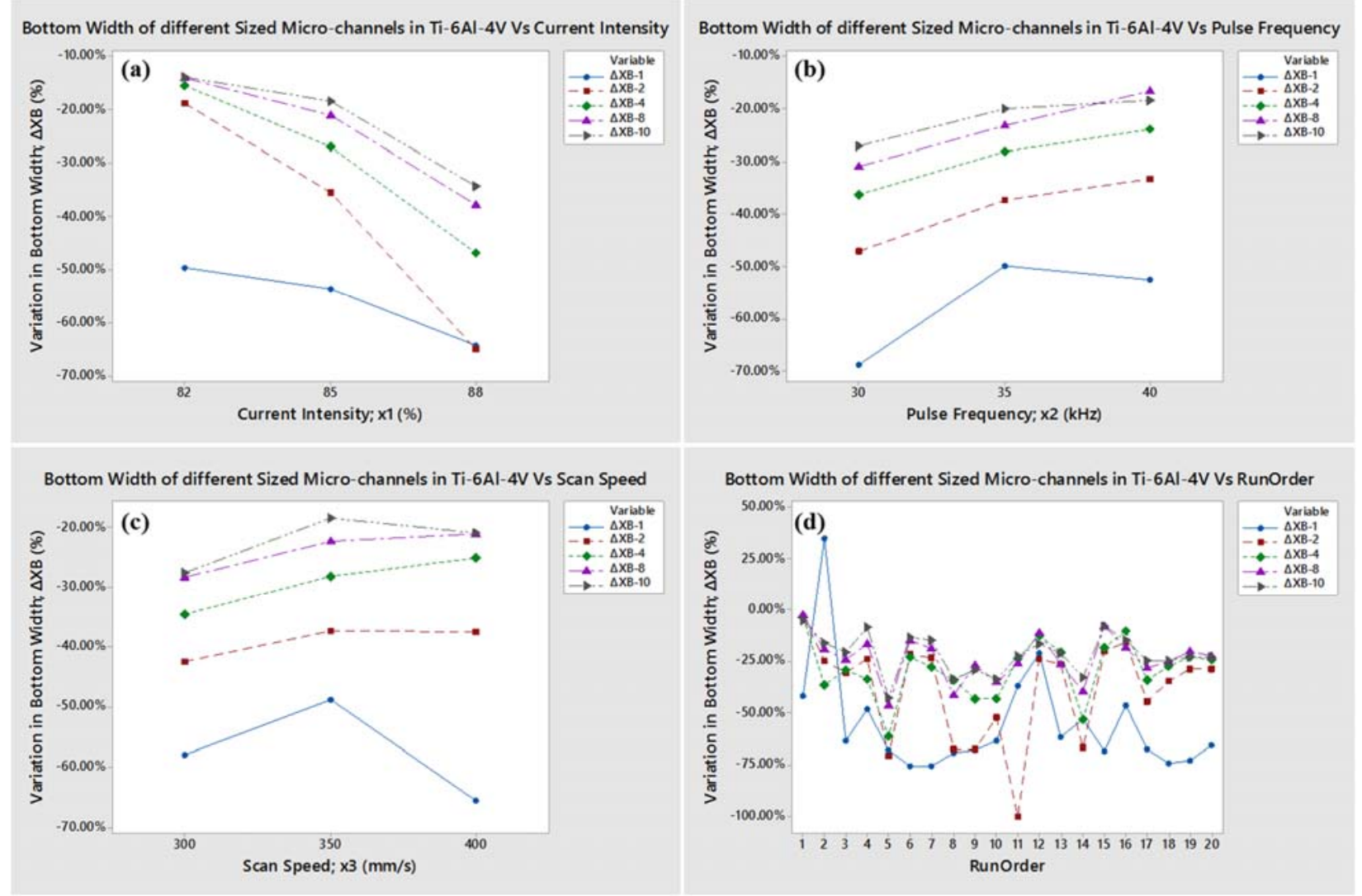

Fig. 10 Variation in bottom width $(\triangle \mathrm{XB})$ of different sized micro-channels Vs; (a) lamp current intensity, (b) pulse frequency, (c) scan speed and (d) run order 


\subsubsection{Effects of Pulse Frequency}

The effects of pulse frequency (x2) on the variation in depth $(\Delta \mathrm{Z})$ are shown in Fig.11 (b). There is a decreasing but rhythmic behaviour of channel depths over the pulse frequency. As the pulse frequency increases the variation in depth of each channel size decreases. For example, using the pulse frequency of $40 \mathrm{kHz}$, as the channel size increases from $100 \times 50 \mu \mathrm{m}$ to $1000 \times 500 \mu \mathrm{m}$ the variation in depths such as $\Delta \mathrm{Z}-1, \Delta \mathrm{Z}-2, \Delta \mathrm{Z}-4, \Delta \mathrm{Z}-\mathrm{8}$ and $\Delta \mathrm{Z}-10$ decreases from $100 \%$ to $0 \%$, respectively. However, for the pulse frequency within the range of $35-40 \mathrm{kHz}$ there is no effect on depth variation for micro-channels of large sizes such as $800 \times 400 \mu \mathrm{m}$ and $1000 \times 500 \mu \mathrm{m}$.

\subsubsection{Effects of Scan Speed}

The effects of scan speed (x3) on depth variation $(\Delta \mathrm{Z})$ is shown in graph (c) of Fig. 11. Irrespective to the level of scan speed, the variation in depth is large if the channel size is small and vice versa. When the channel size is small such as $100 \times 50 \mu \mathrm{m}$ or $200 \times 100 \mu \mathrm{m}$ the laser travelling along width direction is very limited. In such case when the laser scanning over $\mathrm{x}$-direction is confined the laser spot overlapping is high and more heat is produced. This high amount of generated heat aggressively melts the material and consequently the deeper cuts are generated. With a progressing depth the already small area for laser scan becomes more confined due to the propagation of taperness towards channel depth. At this moment, in addition to the excessive heat generation due to more laser overlapping the heat of molten material and plasma pressure also contribute to increase the temperature inside the channel. Thus, the resultant depth achieved after completion of laser scanning cycle is higher than the designed and expected depth. In this way, high variation and/or oversizing in depth is yielded for small sized micro-channels. In case of wider sized channels such as channel sizes $\geq 400 \times 200 \mu \mathrm{m}$, the transverse distance (width wise direction) for laser scan is much abandoned and the contributing factors including spot over lapping, excessive heat generation, taperness, heat dissipation and plasma pressure are minimized due to ample of available transverse space.
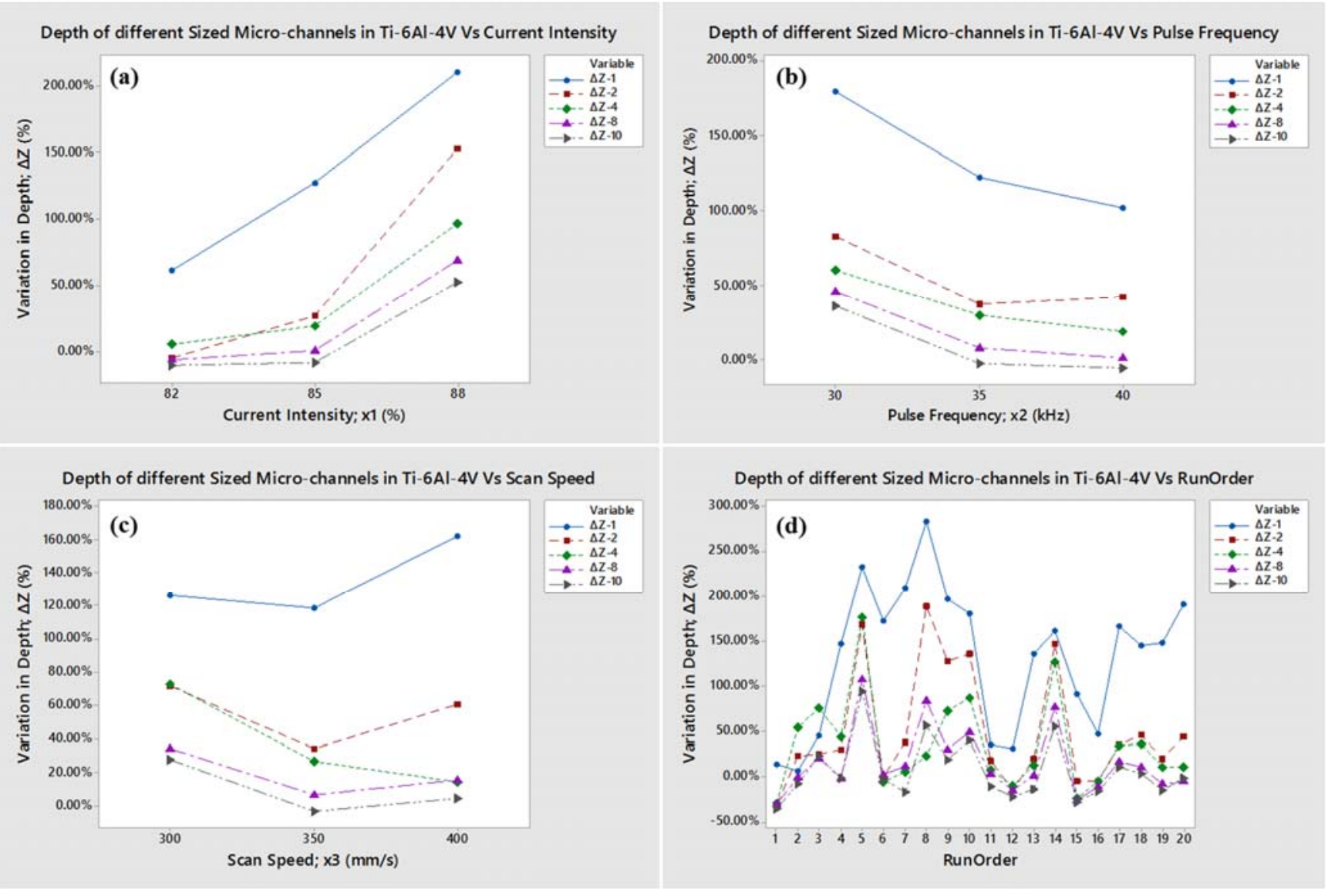

Fig. 11 Variation in Depth $(\Delta Z)$ of different sized micro-channels Vs; (a) lamp current intensity, (b) pulse frequency, (c) scan speed and (d) run order 
While deep machining (e.g. small sized channels), multiple reflections of laser beam from inner side walls of cavity or channel also generated which ultimately increase the energy density and thus more material removal [38]. Furthermore, the material removal rate also depends on the material absorptivity. High is the material absorptivity more will be the material melting and removal and thus more penetration of heat towards depth. The absorptivity of titanium alloys increases with increase in temperature. Absorptivity of Ti-6Al-4V increases from 0.24 to 0.41 as the temperature rises from $500-1400{ }^{\circ} \mathrm{C}$ [35]. Thus, for wider sized channels, the heat dissipation, plasma pressure and accumulation of laser energy distributed over wider area as of result of which the uniform material melting and removal occurs to generate uniform depth of channel. The similar problems are encountered when the scanning speed is at low level allowing high material interaction time and excessive material ablation. Therefore, low level of scan speed $(300 \mathrm{~mm} / \mathrm{s})$ generates high level of variation in depths of micro-channels disregarding to the channel sizes. The oversizing in depths for micro-channels $800 \times 400 \mu \mathrm{m}$ and $1000 \times 500 \mu \mathrm{m}(\Delta \mathrm{Z}-8$ and $\Delta \mathrm{Z}-10)$ are within $0-10 \%$ at scanning speed of $350 \mathrm{~mm} / \mathrm{s}$. However, this speed is more promising to generate lesser amount of oversizing in depths of each sized micro-channel. The behavior of channel depths over the run order performed under RSM design of experimental plan is shown in plot (d) of Fig. 11. The line plot shows that at any setting of laser parameters (over the whole range of experiments performed), the variation in depth of small sized micro-channels is far greater than the variation associated with large sized micro-channels.

\subsection{Dimensional Variation in Taperness $(\Delta \theta)$}

The concept of taperness in laser processes is relatively complex phenomenon and in almost all the kinds of laser beam machining processes the taperness commonly appears. The main reason behind this inherited laser machining problem is the Gaussian shape of laser beam. Though, the taper angle may be somewhat reduced by adjusting the focal length. Samant and Dahotre [39] reduced the tapering effect using a lens of longer focal length and longer focal waist. The calculation of taper angles is performed using previously described equation 4. It shows that the taper angle directly depends on the difference in top and bottom widths and inversely proportional to the depth. The depth plays important role in taper angle calculation due to its inverse relationship.
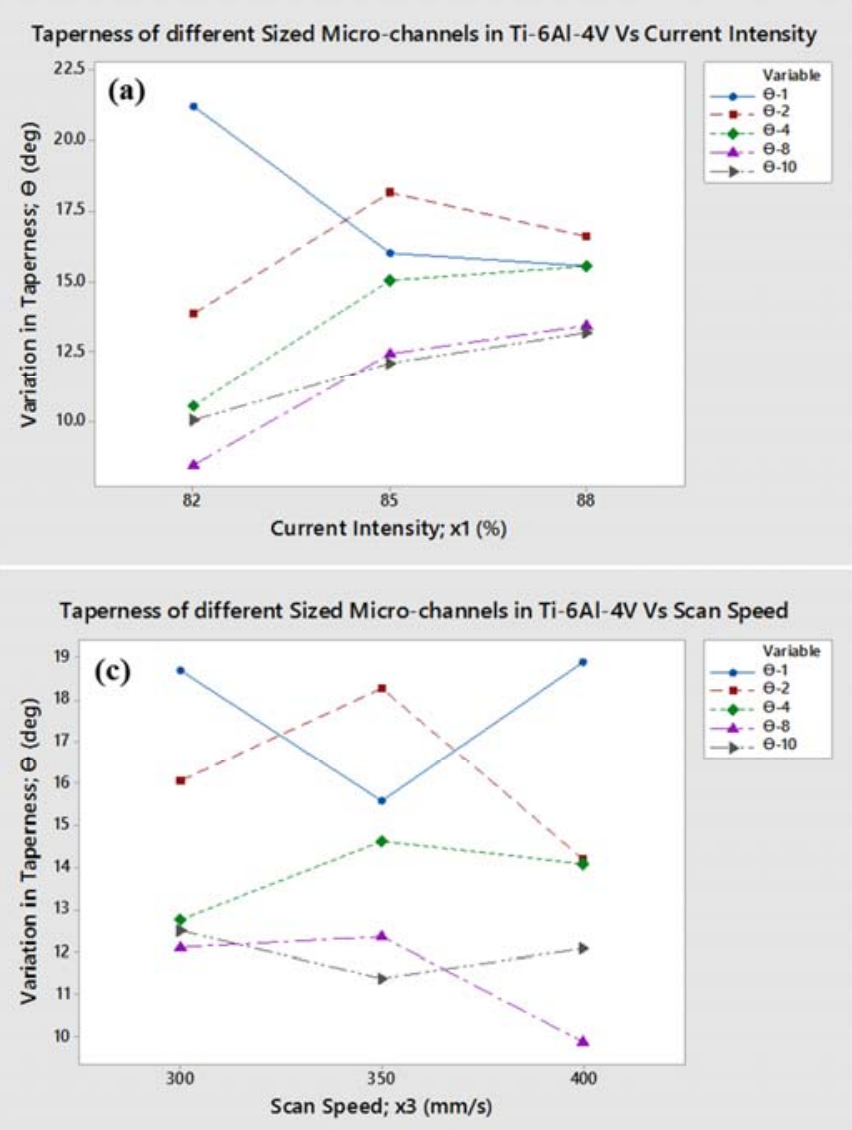

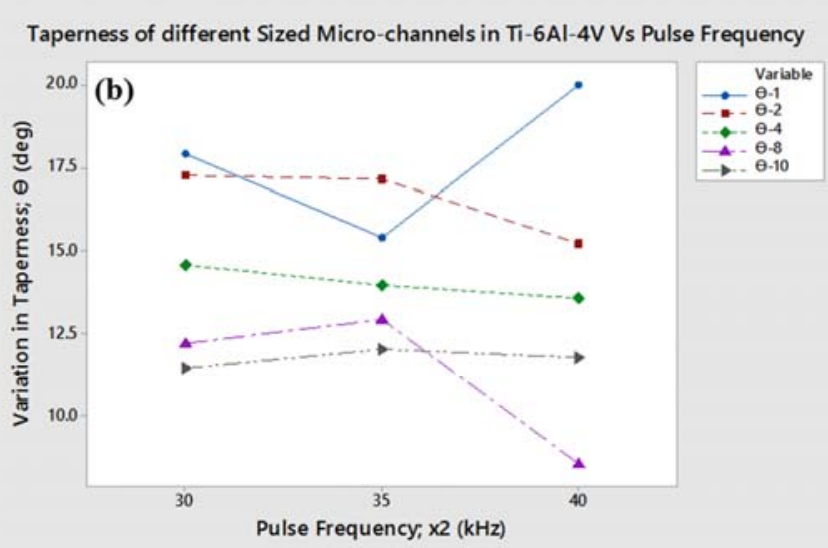

Taperness of different Sized Micro-channels in Ti-6AI-4V Vs RunOrder

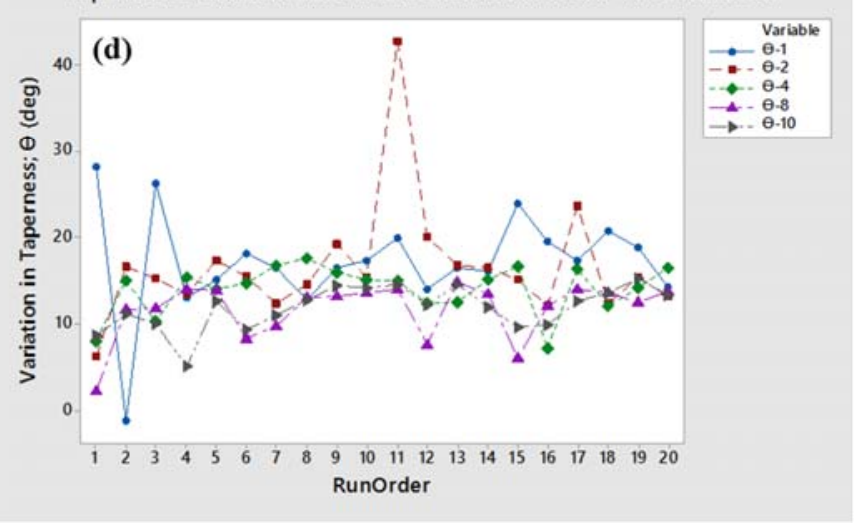

Fig. 12 Variation in taper angle $(\Delta \Theta)$ of different sized micro-channels Vs; (a) lamp current intensity, (b) pulse frequency, (c) scan speed and (d) run order 
There is also a huge variation in micro-channel depths as previously described. Therefore, collectively we cannot expect uniform patterns for taper angles associated with different sized micro-channels. However, the effects of current intensity $(\mathrm{x} 1)$, pulse frequency (x2) and scan speed (x3) on taperness is shown in Fig. 12.

\subsubsection{Effect of Lamp Current Intensity}

Figure 12 (a) demonstrates the effects of lamp current intensity $(\mathrm{x} 1)$ on taperness $(\Theta)$ in different sized microchannels. It is evident that, irrespective to the level of current intensities, the channels of small sizes e.g. 100x50 $\mu \mathrm{m}$ and $200 \times 100 \mu \mathrm{m}$ exhibit high values of taperness compared to large sized channels having relatively less amount of taper angle of micro-channel sidewalls. Coming to the individual level of current intensity, the lowest level of current intensity generates less amount of taper for all the sizes of microchannels. The channels $\geq 400 \times 200 \mu \mathrm{m}$ can be fabricated through laser beam micro-milling (LBMM) with sidewalls taper angle below than 10 degree utilizing current intensity of $82 \%$. However, the current intensity of $88 \%$ generates microchannels of sizes $100 \times 50 \mu \mathrm{m}$ and $200 \times 100 \mu \mathrm{m}$ with taperness of approximately 15 degree.

\subsubsection{Effects of Pulse Frequency}

The effects of pulse frequency (x2) on sidewall taperness $(\Theta)$ is presented in plot (b) of Fig. 12. From the graph it can be seen that the high level of pulse frequency is more suitable to achieve the less degree of taperness for all the channel sizes except for channels $100 \times 50 \mu \mathrm{m}$. However, with respect to the channel sizes, the higher the channel size is the lesser the degree of taperness would be at pulse frequency of $40 \mathrm{kHz}$.

\subsubsection{Effects of Scan Speed}

The impacts of scan speed $(\mathrm{x} 3)$ on taper angle $(\Theta)$ are shown in graph (c) of Fig. 12. The behaviour of taperness is not uniform over the scanning speed levels as well as over the channel sizes. This is mainly because of the variations in depths of micro-channels under the effects of scan speed as briefly explained before. It is not easy to conclude a common statement from this graph. Every channel size has its own lowest degree of taperness against specific scan speed level. However, in order to have a common trend and inference about taperness it is better to speculate the behaviour of taper over the set of experiments performed as shown in Fig. 12 (d) about the graph between taperness vs run order. From this graph it can be inferred that the micro-channel sizes $\geq 400 \times 200 \mu \mathrm{m}$ can be fabricated in Ti-6Al-4V through laser beam micro-milling (LBMM) with an average taper angle ranging within 10-12 degree while the micro-channels $\leq 200 \times 100 \mu \mathrm{m}$ with an average taperness of 15-18 degree.

\subsection{Summary of Results and Discussions}

Based on the laser machining results and the study of dimensional variations, the micro-channels can be classified into two categories; (1) narrow-sized micro-channels $\leq 200 \times 100 \mu \mathrm{m}$, and (2) wider-sized micro-channels $\geq 400 \times 200$ $\mu \mathrm{m}$. Experimental results show the variation of geometric condition is large for narrow-sized micro-channels and small for wider-sized ones. The narrow-sized micro-channels with less amount of variation can be achieved by utilizing some optimization techniques (multi-objective optimization). It is expected to present the results of multi-objective optimization in our future work. The nanosecond and femtosecond lasers (generally used for laser micro-machining) can be used to control the large amount of variation in narrow-sized microchannels. However, while using micro-second laser the microchannel's geometries are entirely depend on the laser parameters as well as on the selection of size. Generally, the low level of current intensity ( $82 \%$ ), low to medium levels of pulse frequency $(30-35 \mathrm{kHz})$ and medium to high levels of laser scan speed $(350-400 \mathrm{~mm} / \mathrm{s})$ can be used to obtain the micro-channels in Ti-6Al-4V with less amount of dimensional variation in the selected geometrical characteristics (top width, bottom width, depth, and taper angle of sidewalls).

\section{Conclusions}

$\mathrm{Nd}$ :YAG pulsed laser having wavelength of $1064 \mathrm{~nm}$ is capable of producing various sized micro-channels in titanium alloy (Ti-6Al-4V). The laser beam micro-milling (LBMM) process causes variation in geometrical characteristics in terms of oversizing and undersizing. Some characteristics are oversized (e.g. top width and depth of channels) whereas some characteristics are undersized (e.g. bottom width of channel). Based on the results and discussion the following corollaries may possibly be drawn:

i. In general, the variation in all the geometrical characteristics are observed in all the sizes of microchannels fabricated in Ti-6Al-4V through Nd:YAG laser beam micro-milling (LBMM). This geometrical variation is large for small sized micro-channels and small for large sized micro-channels.

ii. For all the micro-channel sizes, the actual top width (AXT) and actual depth (AZ) are always oversized compared to designed top width (DXT) and designed depth (DZ). Contrarily, in every size of microchannel the actual bottom width (AXB) is always undersized compared to designed bottom width (DXB).

iii. The variation or oversizing in top width $(\triangle \mathrm{XT})$ is greater for micro-channel sizes $100 \times 50 \mu \mathrm{m}$ and $200 \times 100 \mu \mathrm{m}$ compared to variation for channel sizes $\geq 400 \times 200 \mu \mathrm{m}$. The micro-channels of sizes $\leq$ 200x100 $\mu \mathrm{m}$ exhibit oversizing in top width ranging within $6-20 \%$ and the micro-channels of sizes $\geq$ $400 \times 200 \mu \mathrm{m}$ can be fabricated with an oversizing in top width below than $5 \%$.

iv. The undersizing in bottom width $(\triangle \mathrm{XB})$ of small sized micro-channels (sizes $\leq 200 \times 100 \mu \mathrm{m}$ ) is more as compared to undersizing in large sized channels $(\geq$ $400 \times 200 \mu \mathrm{m})$. The corresponding undersizing ranges 
of these two groups of sizes are $(-60 \%)-(-40 \%)$ and $(-35 \%)-(-10 \%)$, respectively.

v. As the channel size increases the variation or oversizing in depth of micro-channel $(\Delta \mathrm{Z})$ decreases. The variation in depth of $100 \times 50 \mu \mathrm{m}$ channel size $((\Delta \mathrm{Z}-1)$ is highly greater than those of other sizes. The oversizing in depth lies within $60-120 \%$ for this narrow-sized channel. However, the variation in depth of channel sizes $\geq 400 \times 200 \mu \mathrm{m}$ may lies within $5-20 \%$.

vi. Regarding the taperness of sidewalls $(\Theta)$, microchannel sizes $\geq 400 \times 200 \mu \mathrm{m}$ can be fabricated in Ti$6 \mathrm{Al}-4 \mathrm{~V}$ through laser beam micro-milling(LBMM) with an average taper angle of 10-12 degree while the micro-channels of sizes $\leq 200 \times 100 \mu \mathrm{m}$ with an average degree of taperness 15-18 degree.

vii. The appropriate combination of laser parameters promising the less oversizing in top width $(\triangle \mathrm{XT})$ for all the micro-channel sizes could be laser current intensity at $82 \%$, pulse frequency at $35 \mathrm{kHz}$ and scan speed at $350 \mathrm{~mm} / \mathrm{s}$.

viii. Micro-channels with lowest amount of undersizing in bottom width $(\triangle \mathrm{XB})$ for all the micro-channel sizes can be realized using laser current intensity at $82 \%$, pulse frequency at $40 \mathrm{kHz}$ and scan speed at 400 $\mathrm{mm} / \mathrm{s}$.

ix. Current intensity of $82 \%$, pulse frequency of $35 \mathrm{kHz}$ and scan speed of $400 \mathrm{~mm} / \mathrm{s}$ may allow to produce micro-channels of different sizes with lowest oversizing/variation in depth $(\Delta \mathrm{Z})$.

x. Similarly, the ccurrent intensity of $82 \%$, pulse frequency of $35 \mathrm{kHz}$ and scan speed of $400 \mathrm{~mm} / \mathrm{s}$ produce lesser degree of taperness in every size of micro-channel investigated in this study.

\section{Acknowledgment}

The project was financially supported by King Saud University, Vice Deanship of Graduate Studies.

\section{References}

[1] P. Valeh-e-Sheyda, M. Rahimi, E. Karimi, and M. Asadi: Energy Convers. Manag., 69, (2013) 122.

[2] K.F. Jensen: Chem. Eng. Sci., 56, (2001) 293.

[3] D. Deng, W. Wan, Y. Tang, Z. Wan, and D. Liang: Int. J. Heat Mass Transf., 82, (2015) 435.

[4] M.E. Steinke and S.G. Kandlikar: J. Heat Transf., 126, (2004) 518.

[5] M. Richter, P. Woias, and D. Weiß: Sens. Actuators A: Phys., 62, (1997) 480.

[6] M. Ohadi, K. Choo, S. Dessiatoun, and E. Cetegen: "Next Generation Microchannel Heat Exchangers" ed. by F.A. Kulacki, (Springer, New York, 2013) p. 67.

[7] A. Francescon, A. Mapelli, G. Nuessle, P. Petagna, A. Pezous, P. Renaud, and G. Romagnoli: Microelectron. J., 44, (2013) 612.

[8] J. Xu, L. Shi, C. Wang, D. Shan, and B. Guo: J. Mater. Process. Technol., 225, (2015) 375.
[9] D. Gómez and I. Goenaga: Appl. Surf. Sci., 253, (2006) 2230.

[10] S. Prakash and S. Kumar: Int. J. Precis. Eng. Manuf., 16, (2015) 361.

[11] P. Holmberg, V. Pasiskevicius, and M. Fokine: Phys. Status Solidi C, 8, (2011) 2862.

[12] E. Vazquez, D.T. Kemmoku, P.Y. Noritomi, J.V.L. da Silva, and J. Ciurana: Mater. Manuf. Process., 29, (2014) 1494.

[13] Y. Wang, K. Sefiane, and S. Harmand: Exp. Therm. Fluid Sci., 36, (2012) 93.

[14] J. Xu, Y. Gan, D. Zhang, and X. Li: J. Micromechanics Microengineering, 15, (2005) 362.

[15] H.Y. Wu and P. Cheng: Int. J. Heat Mass Transf., 47, (2004) 3631.

[16] L.-J. Yang, Y.-T. Chen, S.-W. Kang, and Y.-C. Wang: Int. J. Mach. Tools Manuf., 44, (2004) 1109.

[17] Y. Madhour, J. Olivier, E. Costa-Patry, S. Paredes, B. Michel, and J.R. Thome: IEEE Trans. Compon. Packag. Manuf. Technol., 1, (2011) 873.

[18] F. Klocke, M. Zeis, A. Klink, and D. Veselovac: CIRP J. Manuf. Sci. Technol., 6, (2013) 198.

[19] D. Dornfeld, S. Min, and Y. Takeuchi: CIRP Ann. Manuf. Technol., 55, (2006) 745.

[20] E. Vazquez, J. Gomar, J. Ciurana, and C.A. Rodríguez: J. Clean. Prod., 87, (2015) 906.

[21] M.P. Jahan, P. Kakavand, E.L.M. Kwang, M. Rahman, and Y.S. Wong: Int. J. Adv. Manuf. Technol., 78, (2014) 1127.

[22] K.P. Rajurkar, M.M. Sundaram, and A.P. Malshe: Procedia CIRP, 6, (2013) 13.

[23] B. Izquierdo, S. Plaza, J.A. Sánchez, I. Pombo, and N. Ortega: Appl. Surf. Sci., 259, (2012) 780.

[24] R. Beach, W.J. Benett, B.L. Freitas, D. Mundinger, B.J. Comaskey, R.W. Solarz, and M. Emanuel: IEEE J. Quantum Electron., 28, (1992) 966.

[25] D. Nieto, T. Delgado, and M.T. Flores-Arias: Opt. Lasers Eng., 63, (2014) 11.

[26] R. Suriano, A. Kuznetsov, S.M. Eaton, R. Kiyan, G. Cerullo, R. Osellame, B.N. Chichkov, M. Levi, and S. Turri: Appl. Surf. Sci., 257, (2011) 6243.

[27] N. Ahmed, S. Darwish, A.M. Alahmari, and K. Salik: Mater. Manuf. Process., 30, (2015) 1290.

[28] E. Vázquez, J. Ciurana, C.A. Rodríguez, T. Thepsonthi, and T. Özel: Mater. Manuf. Process., 26, (2011) 403.

[29] A. Kumar and M.C. Gupta: Opt. Lasers Eng., 48, (2010) 690.

[30] D. Teixidor, I. Ferrer, J. Ciurana, and T. Özel: Robot. Comput.-Integr. Manuf., 29, (2013) 209.

[31] D. Teixidor, T. Thepsonthi, J. Ciurana, and T. Özel: J. Manuf. Process., 14, (2012) 435.

[32] N. Ahmed, S. Darwish, A.M. Alahmari, and M.A. Shar: Int. J. Adv. Manuf. Technol., (2015). DOI 10.1007/s00170-015-7257-1. (In press)

[33] A. Hasçalık and U. Çaydaş: Appl. Surf. Sci., 253, (2007) 9007. 
[34] Y. Ayed, G. Germain, W. Ben Salem, and H. Hamdi: Finite Elem. Anal. Des., 92, (2014) 72.

[35] J. Yang, S. Sun, M. Brandt, and W. Yan: J. Mater. Process. Technol., 210, (2010) 2215.

[36] T.L. Perry, D. Werschmoeller, X. Li, F.E. Pfefferkorn, and N.A. Duffie: J. Manuf. Process., 11, (2009) 74.

[37] H. Ding, N. Shen, and Y.C. Shin: J. Mater. Process. Technol., 212, (2012) 601.

[38] A.N. Samant and N.B. Dahotre: Ceram. Int., 35, (2009) 2093.

[39] A.N. Samant and N.B. Dahotre: J. Manuf. Process., 12, (2010) 1 .

(Received: January 8, 2016, Accepted: May 12, 2016) 